\title{
HEAT TRANSFER AND FRICTION COEFFICIENTS FOR TURBULENT FLOW OF AIR IN SMOOTH ANNULI AT HIGH TEMPERATURES*
}

\author{
M. DALLE DONNE $\dagger$ and E. MEERWALD $\ddagger$
}

(Received 20 June 1972)

\begin{abstract}
Local heat transfer and averaged friction coefficients were measured for subsonic turbulent flow of air through two smooth annuli, with diameter ratios equal to 1.99 and 1.38 , respectively, having the inner tube heated up to temperatures of $1000^{\circ} \mathrm{C}$. The main experimental results can be summarized as follows 1. The local heat-transfer coefficients are correlated by:

$$
N u_{B}=0.018\left(\frac{D_{2}}{D_{1}}\right)^{0.16} R e_{B}^{0.8} \operatorname{Pr}_{B}^{0.4}\left(\frac{T_{W}}{T_{E}}\right)^{-0.2}
$$

which gives the Petukhov and Roizen correlation [13] for low temperature differences $\left(T_{W} / T_{E} \rightarrow 1\right)$. 2. The average heat-transfer coefficients for the inner region of the annulus are correlated by:

$$
N u_{B}=0.0217 R e_{B}^{0.8} P r_{B}^{0.4}\left(\frac{T_{W}}{T_{E}}\right)^{-0.2}
$$

in excellent agreement with data for circular tubes (Dalle Donne--Bowditch correlation [1]).

3. The friction coefficients, both for the whole annulus and the inner region of it, are in excellent agreement with the correlations of Maubach [26] obtained by integration of the universal velocity profile of Nikuradse, provided that density of the fluid is evaluated at the temperature $T_{x}=\sqrt{ }\left(T_{W} \cdot T_{B}\right)$ and the kinematic viscosity at the temperature $T_{W}$, as suggested by the experiments of Taylor for circular tubés [6].
\end{abstract}

\section{NOMENCLATURE}

\section{Geometrical parameters}

$\begin{array}{lll}D_{1}, & \begin{array}{l}\text { diameter of the inner cylinder of } \\ \text { the annulus }[\mathrm{cm}] ;\end{array} & L, \\ D_{2}, & \begin{array}{l}\text { diameter of the outer cylinder of } \\ \text { the annulus }[\mathrm{cm}] ;\end{array} & r_{1}, \\ l, & \begin{array}{l}\text { distance from the inlet of the } \\ \text { section considered (the unheated }\end{array} & r_{2}, \\ & r_{0},\end{array}$

* This paper has been prepared within the framework of the association Euratom-Gesellschaft für Kernforschung $\mathrm{mbH}$., in the field of fast breeder development.

$\uparrow$ Delegated from Euratom to the Fast Breeder Project, Institute of Neutron Physics and Reactor Engineering, Kernforschungszentrum Karlsruhe, West Germany.

¥ Gesellschaft für Kernforschung $\mathrm{mbH}$., Institute of Neutron Physics and Reactor Engineering, Kernforschungszentrum Karlsruhe, West Germany. entrance length not included) $[\mathrm{cm}]$; total length of heated test section $[\mathrm{cm}]$; radius of the inner cylinder of the annulus $[\mathrm{cm}]$

radius of the outer cylinder of the annulus $[\mathrm{cm}]$;

radius at which the two radial universal velocity profiles (from the inner and outer wall of the annulus) intersect, and which separates the inner from the outer region of the annulus $[\mathrm{cm}]$;

$r_{m}$, radius at which the two radial temperatures profiles intersect $[\mathrm{cm}]$; 


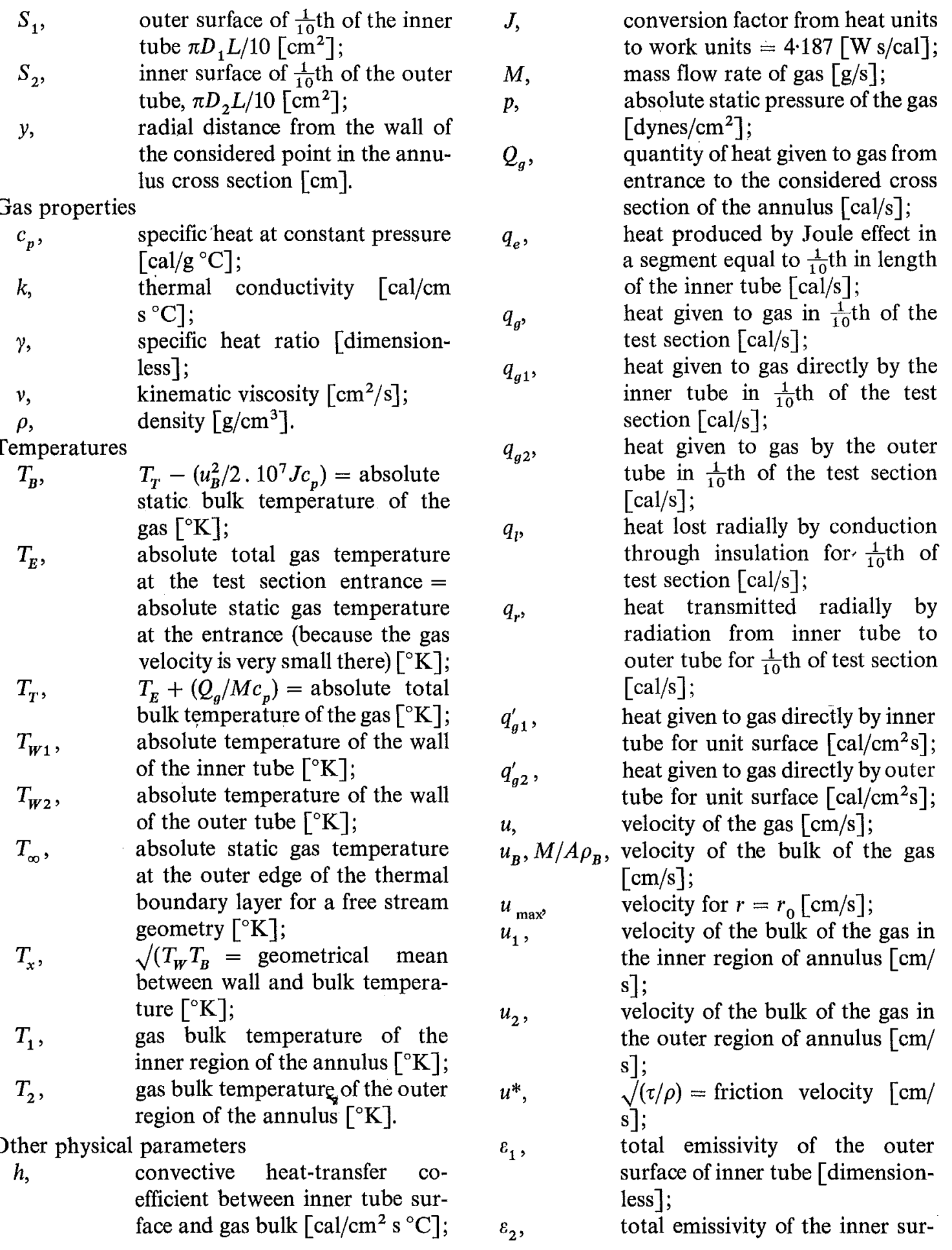


face of the outer tube[dimensionless];

$\begin{array}{ll}\varepsilon_{12}, & \frac{1}{1 / \varepsilon_{1}+S_{1} / S_{2}\left(1 / \varepsilon_{2}-1\right)} \\ & {[\text { dimensionless]; }} \\ \sigma, & \begin{array}{l}\text { Stefan-Boltzmann constant [cal/ } \\ \left.\mathrm{cm}^{2} \mathrm{~s}^{\circ} \mathrm{K}^{4}\right] ;\end{array} \\ & \text { shear stress at the wall [dynes/ } \\ & \mathrm{cm}^{2} \text { ]. }\end{array}$

Dimensionless groups

$f_{B}, 2 \tau / \rho_{B} u_{B}^{2}$, friction coefficient (or friction factor) evaluated at the gas bulk temperature $T_{B}$;

$f_{1}, 2 \tau_{1} / \rho_{1} u_{1}^{2}$, friction coefficient of the inner region of annulus;

$f_{2}, 2 \tau_{2} / \rho_{2} u_{2}^{2}$, friction coefficient of the outer region of annulus;

$M a, u_{B} / \sqrt{ }\left(\gamma p / \rho_{B}\right) ; \quad$ Mach number evaluated at the gas bulk temperature $T_{B}$;

$N u_{B}, h\left(D_{2}-D_{1}\right) / k_{B}, \quad$ Nusselt number evaluated at the gas bulk temperature $T_{B}$;

$\operatorname{Pr}_{B}, v_{B} \rho_{B} c_{p B} / k_{B}$, Prandtl number evaluated at the gas bulk temperature $T_{B}$;

$R e_{B}, u_{B}\left(D_{2}-D_{1}\right) / v_{B}$, Reynolds number evaluated at the gas bulk temperature $T_{B}$;

$R e_{W}, u_{B}\left(D_{2}-D_{1}\right) / v_{W}$, Reynolds number evaluated at the wall temperature $T_{W}$

$R e_{1}, u_{1} \frac{2\left(r_{0}^{2}-r_{1}^{2}\right)}{r_{1}} / v_{1}, \quad$ Reynolds number of the inner region of the annulus evaluated at the temperature $T_{1}$; $R e_{W 1}, u_{1} \frac{2\left(r_{0}^{2}-r_{1}^{2}\right)}{r_{1}} / v_{W}, \quad$ Reynolds number of the inner region of the annulus evaluated at the temperature $T_{W}$;

$u^{+}, u / u^{*}, \quad$ dimensionless gas velocity;

$t^{+}, \frac{\left(T_{W}-T\right) \rho c_{p} u^{*}}{q_{g}^{\prime}}$, dimensionless gas temperature;

$y^{+}, y u^{*} / v$, dimensionless radial distance from the wall;

$\alpha, r_{1} / r_{2}=D_{1} / D_{2}$

$\beta, r_{0} / r_{2}$,
$\gamma, r_{m} / r_{2} \cdot$
$\begin{gathered}\text { Subscripts } \\ B,\end{gathered}$
$W$,
1,
2,
$n$,
$n-1$,
$x$,

gas properties evaluated at the gas bulk temperature $T_{B}$, it refers to the whole of the annulus;

gas properties evaluated at the wall temperature $T_{W}$, it refers to the whole of the annulus;

it refers to the inner region of the annulus;

it refers to the outer region of the annulus;

it refers to the $n$th cross section of the test section;

it refers to the $(n-1)$ th cross section of the test section;

gas properties evaluated at the temperature $T_{x}=\sqrt{ }\left(T_{W} \cdot T_{B}\right)$.

\section{INTRODUCTION}

IN FAST reactor cores very high power densities are present. It is therefore necessary to improve the heat transfer from the fuel elements to the coolant as much as possible, especially with gas cooling, because gas is "per se" not a very good coolant. The fuel element wall temperatures will be rather high. During transients, temperatures as high as $1000^{\circ} \mathrm{C}$ or above are possible. It is therefore of interest to investigate the effect of such high temperatures on heat-transfer coefficient and friction factor for geometries similar to those adopted in fact reactor cores. The temperature effect is already well known for circular tube geometries [1-3], so it was decided to use in the experiment a geometry more similar to the one to be used in the core (bundle of parallel cylindrical rods), but still sufficiently simple to allow accuracy of results and simplification of experimental equipment. The annulus geometry with power production in the central rod is such a geometry. It was felt that not sufficiently reliable data were available regarding temperature effects on annuli, thus an experiment with two annuli with radii ratio 1.38 and 1.99 was planned. 
The first results of this experiment have been already published [4]. Since then the experimental equipment has been improved in many ways, namely:

The test section is vertical and not horizontal thus reducing possible eccentricities between inner and outer tube.

The number of thermocouple measuring the temperature of the internal tube has been increased from 12 to 14 , while 4 of the 14 thermocouples have been placed at the opposite side of the remaining to check for possible excentricities in the annulus.

The number of thermocouples measuring the gas temperature at test section outlet has been increased from 2 to 6 to have a better measurement of the mixed mean gas outlet temperature.

Better instruments were used to measure the electrical heating power. We use now an Amperemeter of the class 0.2 and a Voltmeter of the class 0.5 .

The inner tube supports are now considerably smaller, producing a much reduced temperature variation on the test section. Furthermore, the contact points between the supports and the annulus outer tube are made up of ceramic spheres which allow a relative axial movement of the two concentric tubes without unduly high friction.

Due account is now taken during the calculations of the friction and heat transfer coefficients of the dimensional changes in both tubes with temperature.

All these improvements have practically eliminated the effect of eccentricities between inner and outer tube and of the bowing of the inner tube on our experimental results. In presence of significant temperature differences between inner tube thermocouples placed at opposite sides, the test was rejected. Furthermore, the heat balances in the present experiments were considerably better than those relative to the experiments reported in [4]. All this has as a consequence that the correlations obtained in the present paper differ quite con- siderably from those reported in [4]. For the reasons stated above and also because the present results agree much better with theoretical considerations as we will see in the present paper, we consider the correlations of [4] as superseded by the present ones.

The program of the present experiment includes the study of the effect of high temperatures on artificial roughness, which is also of great importance for gas or superheated steam cooled fast reactor cores. These experiments have been performed and are being evaluated. Their results will be published in the next few months.

Although the gases foreseen as possible reactor coolants are helium, $\mathrm{CO}_{2}$ or water superheated steam as in the experiments of [4], air is the coolant used in the present experiment. This simplifies the experiment very much. In [1] and [2] it has been shown that it is possible to obtain with air formulae valid for other gases as well, also for convective heat transfer in the presence of high temperature differences between wall and gas, provided the correlation formulae are chosen properly.

\section{APPARATUS AND PROCEDURE}

A turboblower driven by an electrical motor delivers air successively through an orifice plate assembly to measure flow rate, an adiabatic entrance length, an annulus formed by a stainless steel heater rod supported concentrically in a tube, and finally to atmosphere.

Electrical supply for the test section is obtained from a fixed ratio transformer $(40 \mathrm{~V}, 2000 \mathrm{~A}$ maximum), the primary winding of this transformer being supplied by a voltage regulator, the output voltage of which may be varied from 0 to $220 \mathrm{~V}$. The voltage regulator is connected to the supply net through a voltage stabilizer. Thus there is the possibility of varying continuously the power supply from 0 to $80 \mathrm{~kW}$ and to keep constant within \pm 0.5 per cent any value in this range.

The temperature of the internal tube heated surface is measured by means of 14 Platinel thermocouples introduced in the center of the 
heater element and electrically insulated with twin bore alumina tubing and then inserted into the wall of the stainless steel tube where they are peened over.

The outside tube of the annulus is insulated by a $50 \mathrm{~mm}$ thick calcium silicate slab contained between two layers of asbestos tape each about $7 \mathrm{~mm}$ thick. Twenty-two $\mathrm{CrNi} / \mathrm{Ni}$ thermocouples are welded to the outer surface of this tube.

In five sections each $400 \mathrm{~mm}$ apart along the test section are placed static pressure measuring devices. In each section there are four pressure taps spaced at $90^{\circ}$. Thus one has the average static pressure in the section independently from local dissymmetries. In practice the four measured values in any section differed very little.

The gas temperatures at the inlet and at the outlet of the test section were measured respectively by means of a bare Platinel and seven $\mathrm{Cr} / \mathrm{Ni}$ thermocouples, of which the four nearest to the test section outlet were shielded.

The gas temperature measurements were checked at every test by means of a comparison between the measured electrical power and the thermal power (heat to gas, plus heat losses through insulation). Tests with heat balances more than 5 per cent out were rejected.

The distribution of the power produced by Joule effect in the heater rod is known by measuring the voltage distribution along the tube. One leg of each thermocouple fixed on the inner tube is used as a voltage tapping.

The static calibration allowed also the measurement of the relative total emissivity $\varepsilon_{12}$ between the two concentric tubes as a function of temperature. For the central portion of the test section where the temperatures $T_{W 1}$ and $T_{W 2}$ are constant, one can assume with a good approximation that the heat is transmitted by radiation in radial direction only. Thus one can use the formula valid for infinitely long concentric tubes

$$
q_{r}=\frac{\sigma S_{1}}{\frac{1}{\varepsilon_{1}}+\frac{S_{1}}{S_{2}}\left(\frac{1}{\varepsilon_{2}}-1\right)}\left(T_{W 1}^{4}-T_{W 2}^{4}\right)
$$

$$
=\varepsilon_{12} \sigma S_{1}\left(T_{W 1}^{4}-T_{W 2}^{4}\right) .
$$

The emissivity coefficient depends on both temperatures $T_{W 1}$ and $T_{W 2}$, but, in first approximation, $\varepsilon_{12}=\varepsilon_{1}$ because $S_{1} / S_{2}<1$ and we can assume that $\varepsilon_{12}$ depends only on $T_{W 1}$. With the static calibration and the use of equation (1) it is possible to give $\varepsilon_{12}$ as a function of $T_{W 1}$ for any test section.

During the tests the temperatures of inner and outer tubes, the voltage distribution along the inner tube and the pressure distribution along the annulus were measured.

The bulk gas total temperature was calculated in the following way. The test section is divided into ten equal parts along the length. For each part the heat produced in the inner tube by Joule effect $\left(q_{e}\right)$ is calculated, knowing the electrical current and the voltage drop in that particular section. From the average value of $T_{W 2}$ of the section and the heat losses curve given by the static calibration one obtains the heat loss through the lagging $\left(q_{1}\right)$. The difference between heat produced and heat lost gives the heat to the gas $\left(q_{g}\right)$. Dividing this by the gas mass flow one obtains the increment in enthalpy of the gas in this section. The gas enthalpy at the inlet of the annulus is obtained from the gas temperature and pressure which are known. From the gas enthalpy and pressure distribution along the test section, one can calculate the total gas bulk temperature along the annulus.

To calculate the heat which goes by convection from the inner tube directly to the gas, it was necessary to subtract from $q_{g}$ the heat which goes by radiation from the inner tube to the outer-tube and then by convection from the outer tube to the gas $\left(q_{g 2}\right), q_{g 2}$ is given by the difference between $q_{r}$, which one can obtain knowing $T_{W 1}, T_{W 2}, \varepsilon_{12}$ (from the static calibration) and $q_{l}$. Thus:

$$
\begin{gathered}
q_{g 1}=q_{g}-q_{g 2}=q_{g}-\left(q_{r}-q_{l}\right)=q_{e}-q_{l} \\
-q_{r}+q_{l}=q_{e}-q_{r}
\end{gathered}
$$

The friction coefficients were calculated from the equation: 


$$
f=-\frac{D_{2}-D_{1}}{2 p \gamma M a^{2}} \frac{\partial}{\partial l}\left[p\left(1+\gamma M a^{2}\right)\right]
$$

which requires the measurement of gas mass flow, pressure, and total gas temperature along the test section. This equation takes into account the pressure drop due to acceleration. Its derivation is shown in [4].

In the calculation of the heat transfer and friction coefficients, attention was confined to the central portion of the test section, where the heat flux to the gas was almost constant and the effect of conduction of heat along the test section walls was negligible. Calculations were performed for four stations, $60,100,140$ and $180 \mathrm{~cm}$ distant from the point where the heating starts. All the average values given in the paper are relative to the three latter cross sections, the first being still affected by inlet effects.

More detailed information on the apparatus and on methods used to analyse the experimental data is reported in [4].

\section{EXPERIMENTAL RESULTS}

\subsection{Friction factors}

Figure 1 shows the average friction factor vs. Reynolds number, all the gas physical properties being evaluated at the gas bulk temperature. The local friction factors are affected by considerable higher scatter due to the smaller measured pressure drop. The error in the measurement and, consequently, the scattering of the points is reduced for the average friction factors because those refer to greater measured pressure drops. The following points are of interest:

The experimental points agree very well with the Prandtl-Nikuradse law of friction for smooth pipes for $R e_{B} \geqslant 10^{5}$, [5], while for $R e_{B}=10^{4}$ they are about 15 per cent higher. The agreement with a theroetical line, valid for our annuli and with which we will deal in section 4 , is better (10 per cent difference at $R e_{B}=10^{4}$ ).

No systematic difference within the accuracy of the experiment can be noticed between the two annuli.

No systematic difference can be noticed between isothermal friction coefficients and coefficients with heat transfer up to the maximum measured temperature of $1000^{\circ} \mathrm{C}$.

This last point has a general character and deserves some comments. Taylor has recently correlated a large number of friction factors from many different authors for both laminar and turbulent flow of gases through a smooth tube with surface to fluid bulk temperature ratios from 0.35 to 7.35 [6]. While for the laminar flow he found that the friction coefficients could be predicted by the Dalle Donne-Bowditch relationship:

$$
f_{B}=\frac{16}{R e_{W}}[1,3]
$$

for the turbulent regime he suggested the correlation:

$$
\frac{f_{B} \sqrt{ }\left(T_{W} / T_{B}\right)}{2}=0.0007+\frac{0.0625}{R e_{W}^{0.32}} .
$$

For the gases considered (air, nitrogen, carbon dioxide, helium and hydrogen) one can write with good approximation:

$$
\begin{gathered}
\frac{\mu_{W}}{\mu_{B}} \cong\left(\frac{T_{W}}{T_{B}}\right)^{0.7} \\
\frac{\rho_{W}}{\rho_{B}} \cong \frac{T_{B}}{T_{W}}
\end{gathered}
$$

thus

$$
R e_{B}=R e_{W}\left(\frac{T_{W}}{T_{B}}\right)^{1 \cdot 7}
$$

and equation (5) becomes:

$\frac{f_{B}}{2}=0.0007\left(\frac{T_{W}}{T_{B}}\right)^{-0.5}+\frac{0.0625}{R e_{B}^{0.32}}\left(\frac{T_{W}}{T_{B}}\right)^{-0.04}$

which is in the Reynolds number and temperature ratio ranges of the present experiment $\left(8 \times 10^{4} \leqslant R e_{B} \leqslant 2 \times 10^{5} ; 1 \cdot 3 \leqslant T_{W} / T_{B} \leqslant 2 \cdot 6\right)$ practically coincident with the Prandtl-Niku- 


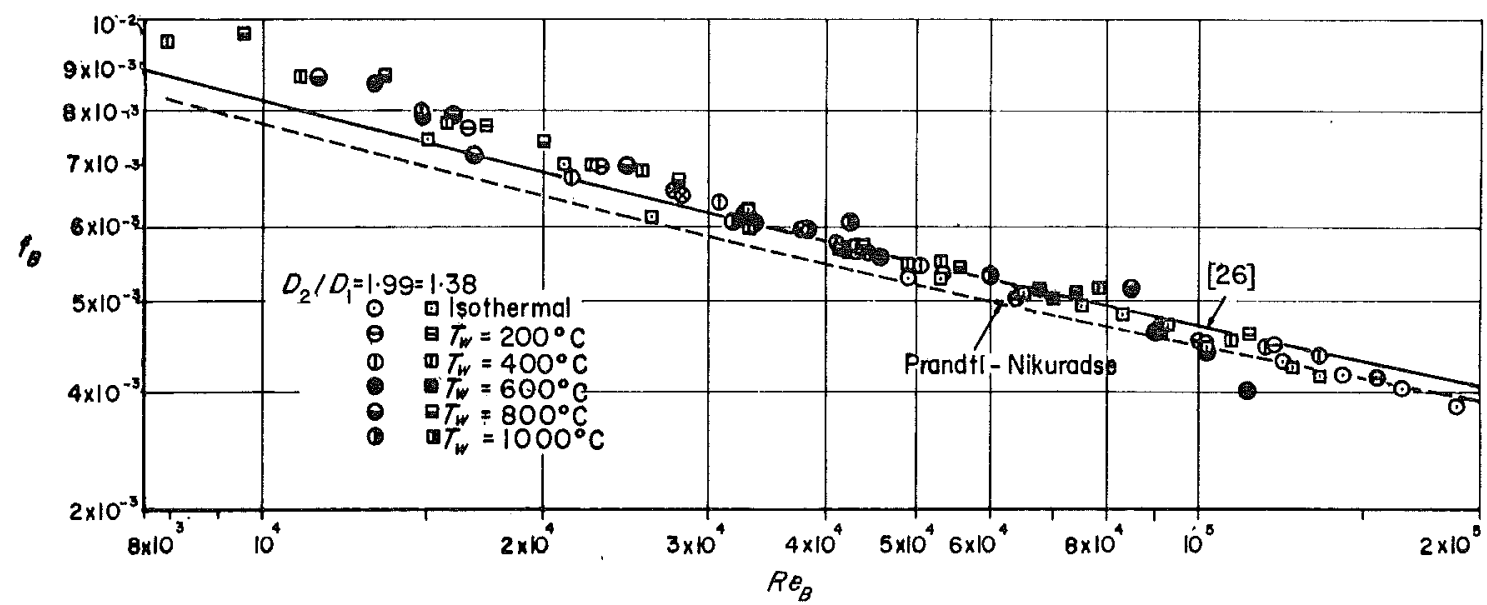

FIG. 1. Average friction factors vs. Reynolds number.

radse law of friction with all the gas properties evaluated at the gas bulk temperature:

$$
\frac{1}{\sqrt{ }\left(f_{B}\right)}=4 \log \left[R e_{B} \sqrt{ }\left(f_{B}\right)\right]-0.40 .
$$

This is confirmed by Figs. 2 and 3 which show the friction factors with heat transfer obtained in the present experiment both in the plot $f_{B}$ vs. $R e_{B}$ and $f_{B} \sqrt{ }\left(T_{W} / T_{B}\right)$ vs. $R e_{W}$. For both annuli, no systematic difference can be noticed between the two correlation systems. However; in the larger Reynolds number and temperature ratio ranges considered by Taylor, equation (5) is necessary to correlate all the experimental points. It is interesting to notice that the correlation system $f_{B} \sqrt{ }\left(T_{W} / T_{B}\right)$ and $R e_{W}$ is equivalent to assume that the friction velocity which appears in the universal velocity distribution is:

$$
u^{*}=\sqrt{ }\left(\tau / \rho_{x}\right)
$$

where $\tau=f_{B}\left(\rho_{B} u_{B}^{2} / 2\right), \rho_{x}$ is evaluated at $T_{x}=$ $\sqrt{ }\left(T_{W} . T_{B}\right)$, while the kinematic viscosity is evaluated at $T_{W}$. If these definitions are used, the universal velocity distribution remains the same

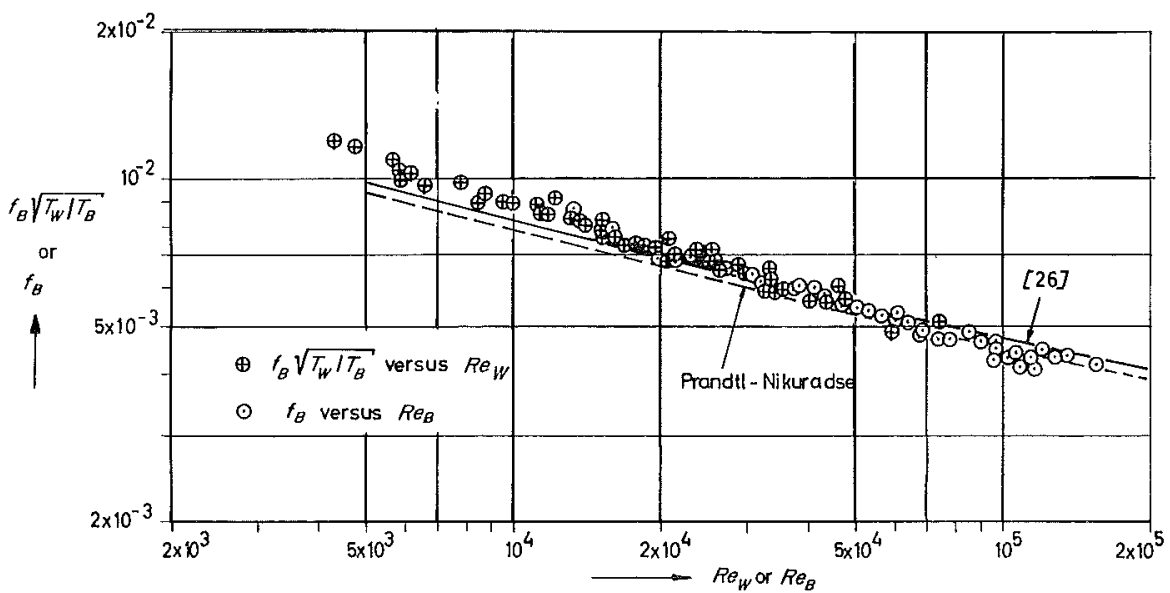

FIG. 2. Average friction factors; Taylor's correlation, $D_{2} / D_{1}=1.99$. 


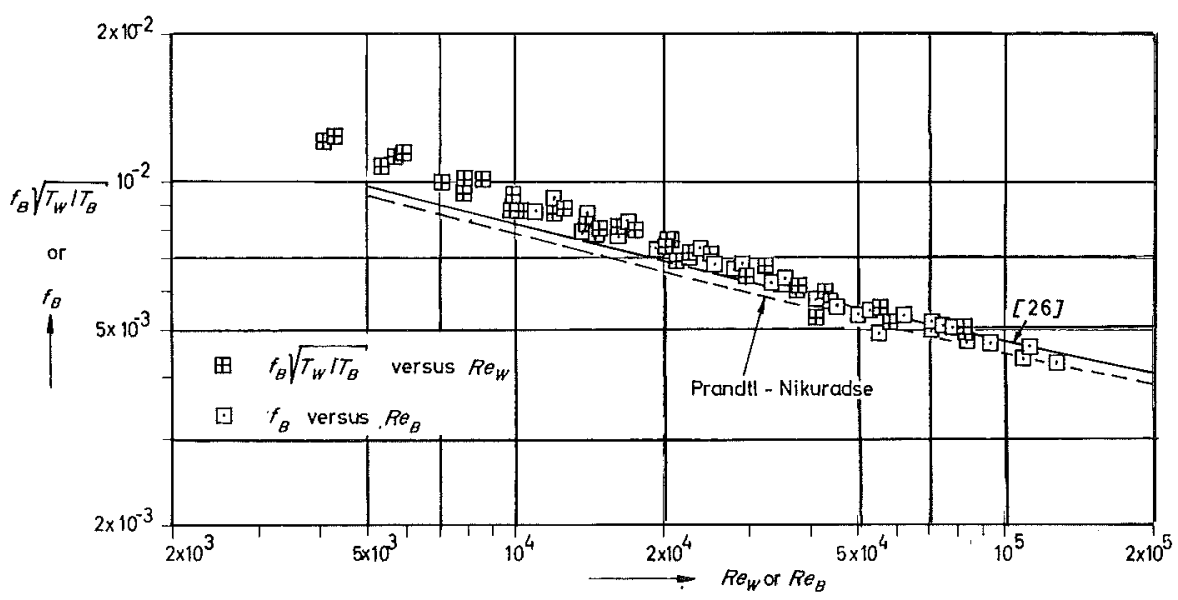

FIG. 3. Average friction factors; Taylor's correlation $D_{2} / D_{2}=1 \cdot 38$.

in presence of large temperature differences between wall and gas as in the case of isothermal flow.

3.2 Heat transfer coefficients. Correlation with $\mathrm{T}_{\mathrm{W}} / \mathrm{T}_{\mathrm{B}}$

Figures 4-9 show the ratio $N u_{B} / R e_{B}^{0 \cdot 8} \operatorname{Pr}_{B}^{0.4}$ vs. $T_{W} / T_{B}$ for various $l / D$ 's and two different values of $D_{2} / D_{1}$. In this, one assumes that the
Reynolds number effect is at the exponent 0.8 , how it was found by almost all the previous authors for fluids in turbulent regime, and the Prandtl number effect is at the exponent 0.4 . The exponent of $P r_{B}$ is usually taken as 0.4 although in some cases other values are given. Due to the very small variations of the Prandtl number of gases the precision with which it is possible to measure this exponent is very low.

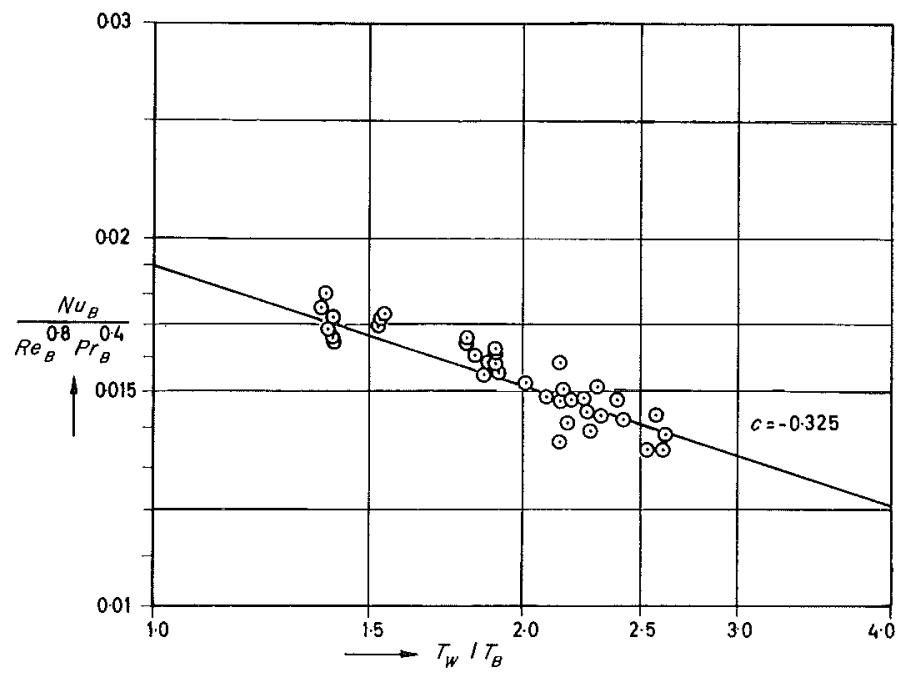

Fig. 4. Local heat transfer coefficients vs. $T_{W} / T_{B}, D_{2} / D_{1}=1 \cdot 99 ; l / D=40 \cdot 3$. 


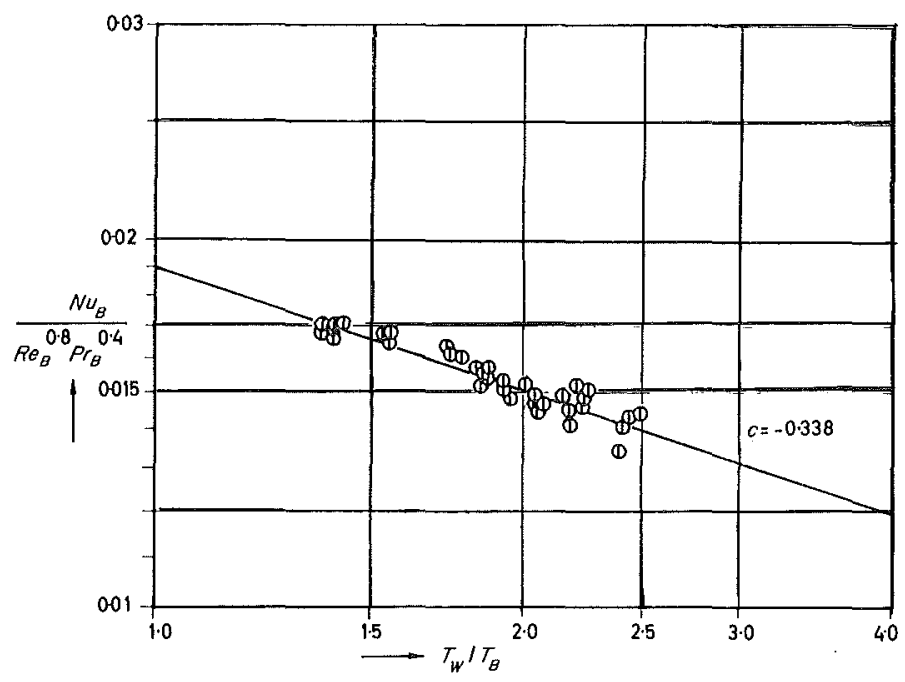

Fig. 5. Local heat transfer coefficients vs. $T_{W} / T_{B}, D_{2} / D_{1}=1.99 ; l / D=56.5$.

Conversely its variations have little effect on heat-transfer coefficients, e.g. the sometimes used value 0.33 makes only 2.5 per cent difference on $N u_{B}$.

As many authors before, we used the ratio $T_{W} / T_{B}$ to take into account the effect of the variations of fluid properties in any section of the annulus due to large temperature differences between wall and gas temperatures.
From the figures one can see that the equations which correlate the experimental points are the following:

$$
\begin{aligned}
N u_{B}=0.0190 R e_{B}^{0.8} \operatorname{Pr}_{B}^{0.4}\left(\frac{T_{W}}{T_{B}}\right)^{-C} \\
\text { for } \frac{D_{2}}{D_{1}}=1.99
\end{aligned}
$$

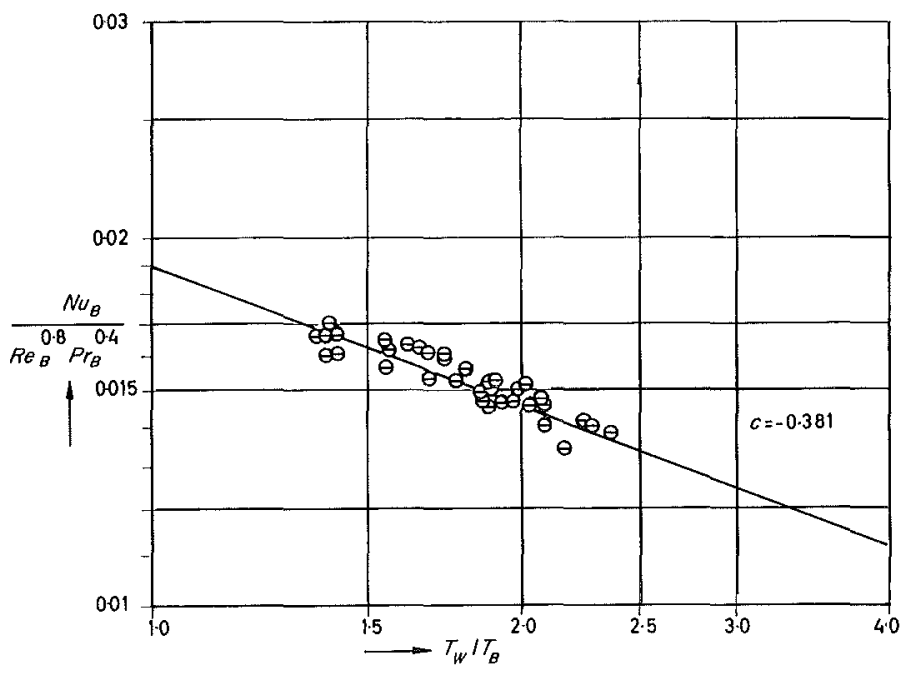

Frg. 6. Local heat transfer coefficients vs. $T_{W} / T_{B}, D_{2} / D_{1}=1 \cdot 99 ; l / D=72 \cdot 6$. 


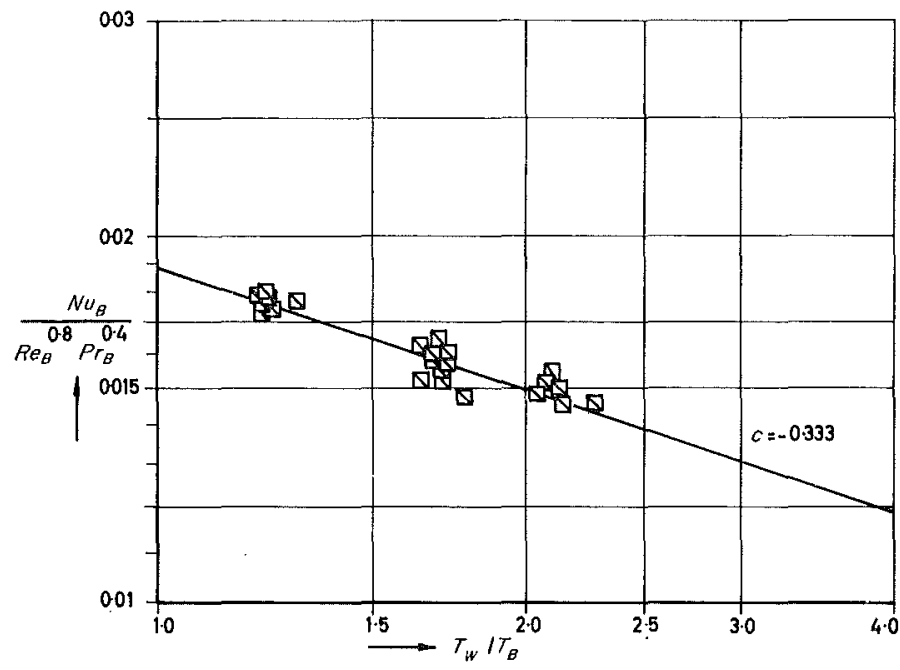

Fig. 7. Local heat transfer coefficients vs. $T_{W} / T_{B}, D_{2} / D_{1}=1 \cdot 38 ; l / D=52 \cdot 3$.

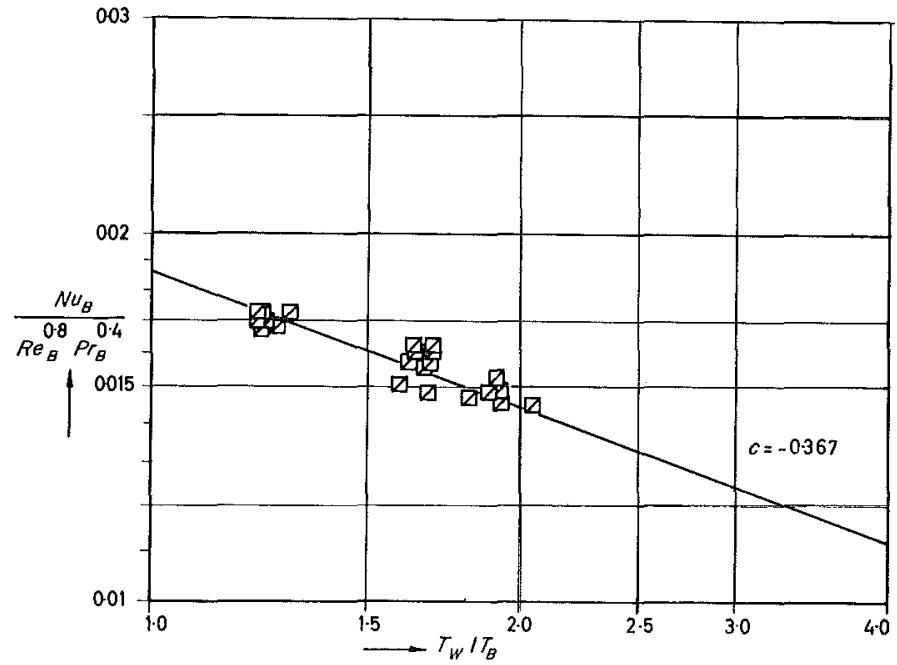

FIG. 8. Local heat transfer coefficients vs. $T_{W} / T_{B}, D_{2} / D_{1}=1 \cdot 38 ; l / D=73 \cdot 2$. 


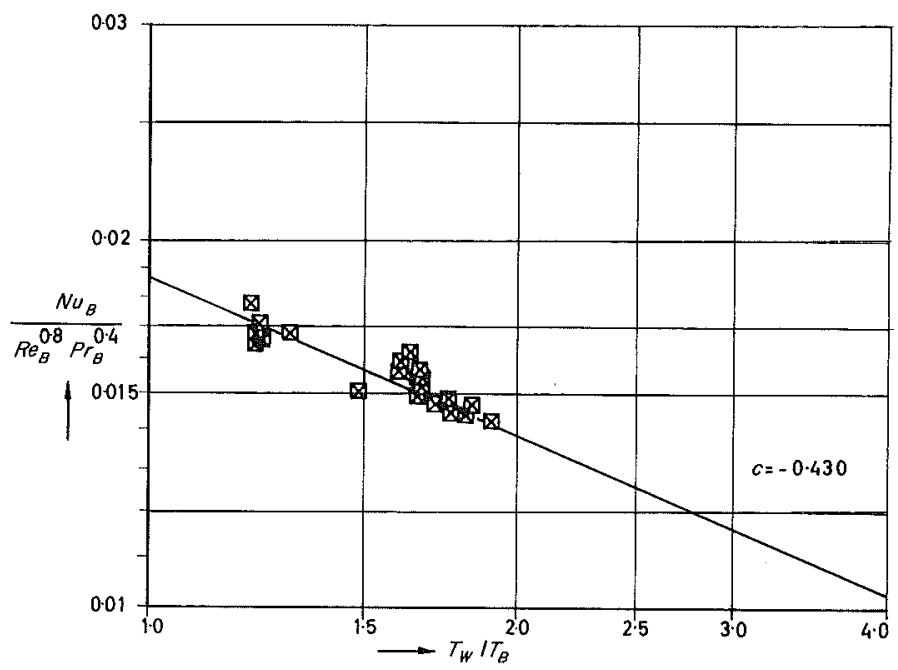

FIG. 9. Local heat transfer coefficients vs. $T_{F H} / T_{B}, D_{2} / D_{1}=1 \cdot 38 ; 1 / D=94 \cdot 1$.

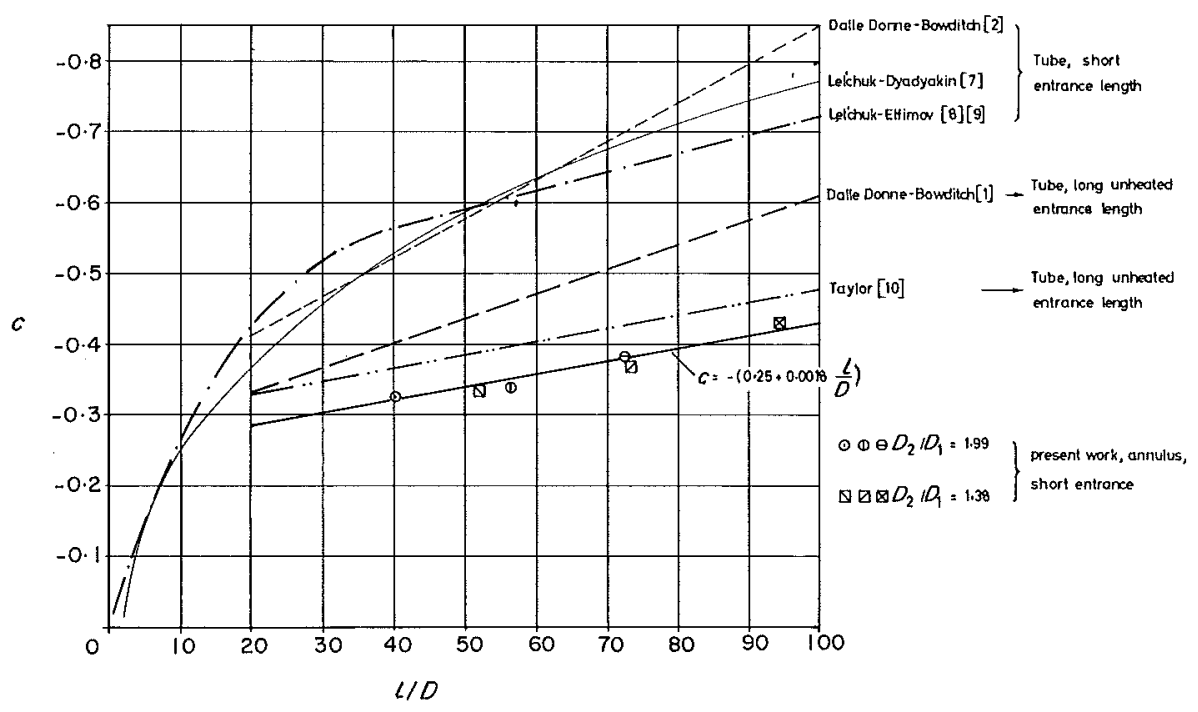

Fig. 10. The exponent $C$ vs. $l / D$. 
and

$$
\begin{aligned}
N u_{B}=0.0186 R e_{B}^{0.8} \operatorname{Pr}_{B}^{0.4}\left(\frac{T_{W}}{T_{B}}\right)^{-C} \\
\text { for } \frac{D_{2}}{D_{1}}=1.38
\end{aligned}
$$

where the exponent $C$ is a function of $l / D$. Figure 10 shows the exponent $C$ vs. $l / D$ for the experiments reported in the present paper and from various other authors for flow inside a pipe. The values of $C$, obtained in the present work for the two annuli investigated, lay below the values for the tube geometry, the general tendence to increase linearly with $l / D$ being maintained. It should be noticed that the uncertainty assigned to $C$ is considerable due to the difficulty to determine the value of the factor

$$
A=\left(\frac{N u_{B}}{R e_{B}^{0 \cdot 8} \cdot \operatorname{Pr}^{0 \cdot 4}}\right)_{T_{W} / T_{B}=1} .
$$

However, the discrepancy between the various curves of Fig. 10 is probably more apparent than real, because to greater values of $C$ correspond for different authors greater values of $A$. These two differences compensate in fact each other, so that the values of $N u_{B} / \operatorname{Re}_{B}^{0.8} \mathrm{Pr}^{0.4}$, in the region where most measurements lay $\left(1.5 \leqslant\left(T_{W} / T_{B}\right) \leqslant 2\right)$, are much closer than Fig. 10 would at first sight indicate.

Figure 11 shows the factor $A$ vs. $D_{1} / D_{2}$ from experiments and theories of many different authors. Of the experimental points of Puchov and Vinogradov [12] only those for $L / D>45$ have been plotted in Fig. 11, assuming that in the other test sections shorter than $L / D=30$, no really fully established flow was reached. The empirical correlation of Petukhov and Roizen [13] describes quite well the experimental points, inclusive of the two obtained in the present work:

$$
A=0.018\left(\frac{D_{2}}{D_{1}}\right)^{0 \cdot 16 \xi}
$$

where

$$
\xi=1 \text { for } \frac{D_{1}}{D_{2}} \geqslant 0 \cdot 2
$$

and

$$
\xi=1+7 \cdot 5\left(\frac{D_{2} / D_{1}-5}{R e_{B}}\right)^{0.6} \text { for } \frac{D_{1}}{D_{2}}<0.2 .
$$

$\xi$ is a correction factor accounting for the fact that according to the data of Petukhov and Roizen the exponent of the Reynolds number is smaller than 0.8 at $D_{1} / D_{2} \leqslant 0 \cdot 143$.

The correlation of Barthels [14] and of Buleev, Molosova and Eltsova [17, 18] agree reasonably well with equation (14), while Rapier [11] tends to give too low values of $A$, especially in the region of small $D_{1} / D_{2}$ 's. The two experimental points of Furber, Green and Vivian [20] would lay considerably above the PetukhovRoizen line. This is very likely due to the fact that in this experiment the fully established flow was not reached.

\subsection{Heat transfer coefficients. Correlation with $\mathrm{T}_{\mathrm{W}} / \mathrm{T}_{\mathrm{E}}$}

In recent time the ratio $T_{W} / T_{E}$ has been used in place of $T_{W} / T_{B}$ to correlate high temperature heat-transfer coefficients with forced convection of gases in tubes $[1-4,21]$. This was done to try to eliminate the $l / D$ effect on the exponent $C$. It was thought that the temperature profile, in analogy to the velocity profile, would become fully established after 15-30 diameters in turbulent regime, thus the $l / D$ effect on $C$ at values as high as $l / D=300$ [1] would have been given by the wrong choice of the temperature parameter rather than by a real entrance or boundary effect.

The choice of the parameter $T_{W} / T_{E}$ was suggested by the comparison of the growth of the thermal boundary layer in a duct (closed geometry) and along a flat plate (free-stream geometry). For a free stream geometry the temperature-dependent fluid properties are accounted by the ratio $T_{W} / T_{\infty}$. Because for a 


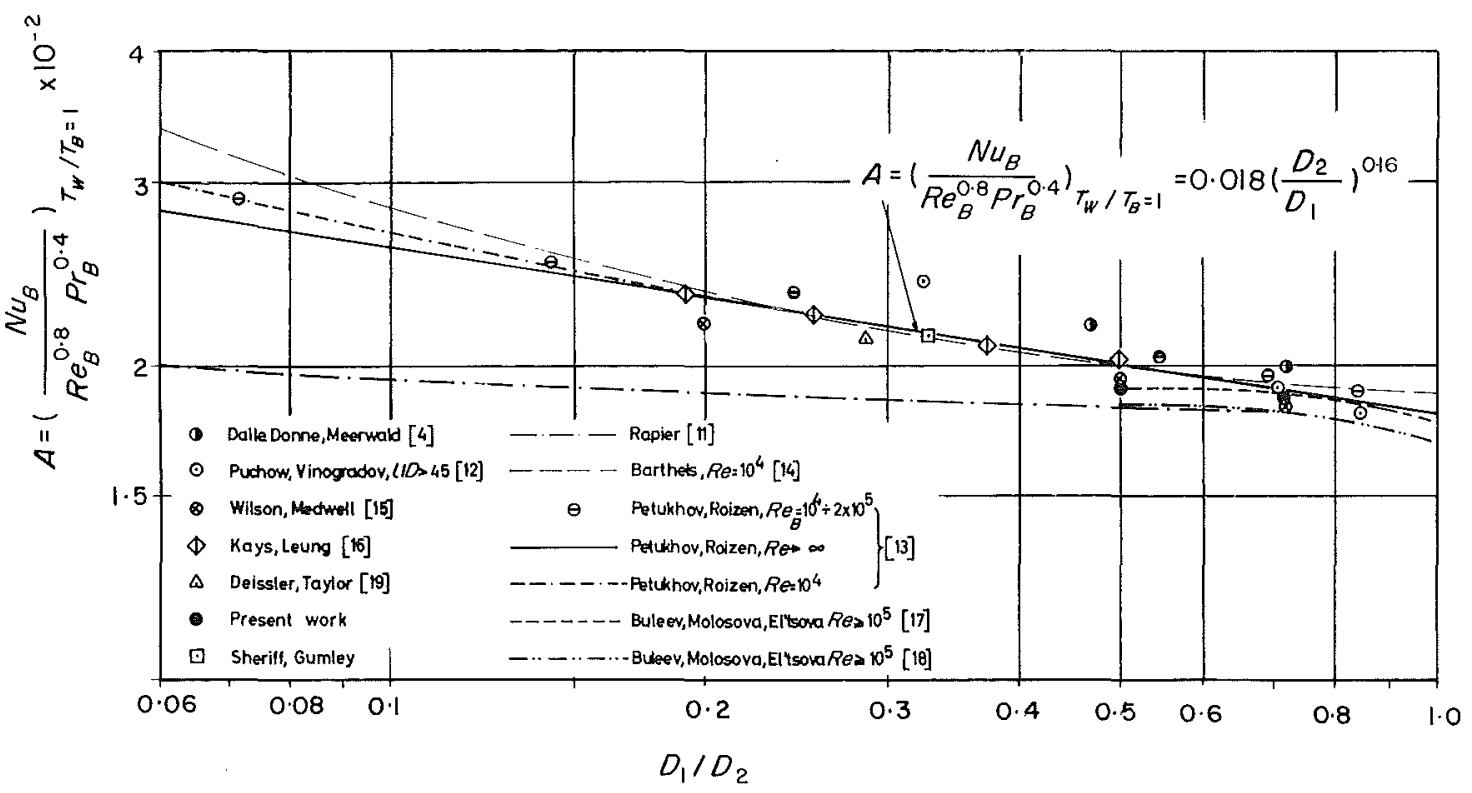

FIG. 11. The factor $A=\left(\frac{N u_{B}}{\operatorname{Re}_{B}^{0 \cdot 8} \operatorname{Pr}_{B}^{0 \cdot 4}}\right)_{T_{W} / T_{B}=1}$ vs. $D_{1} / D_{2}$.

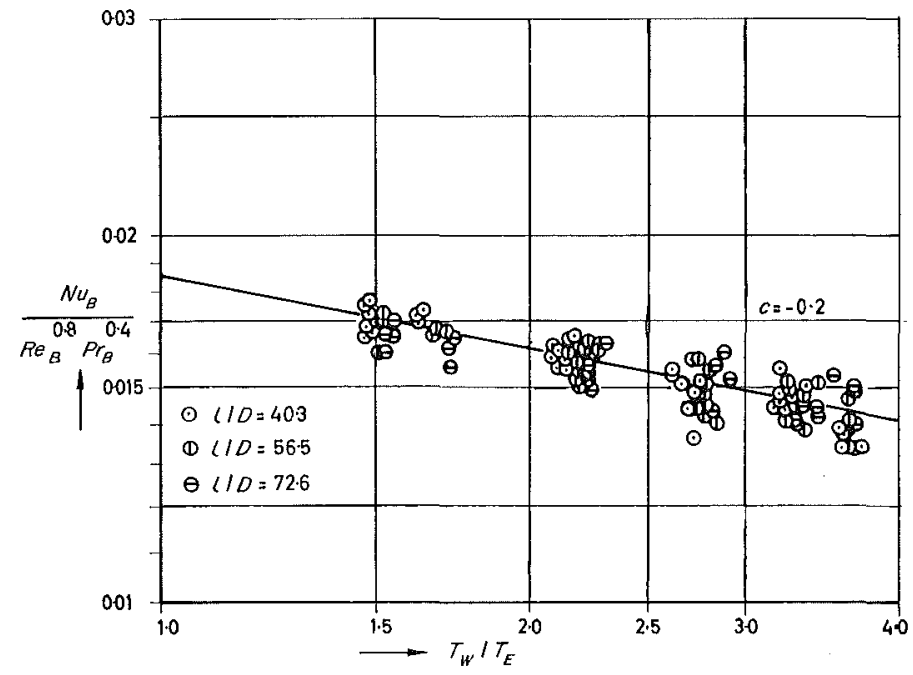

FIG. 12. Local heat transfer coefficients vs. $T_{W} / T_{E}, D_{2} / D_{1}=1.99$. 


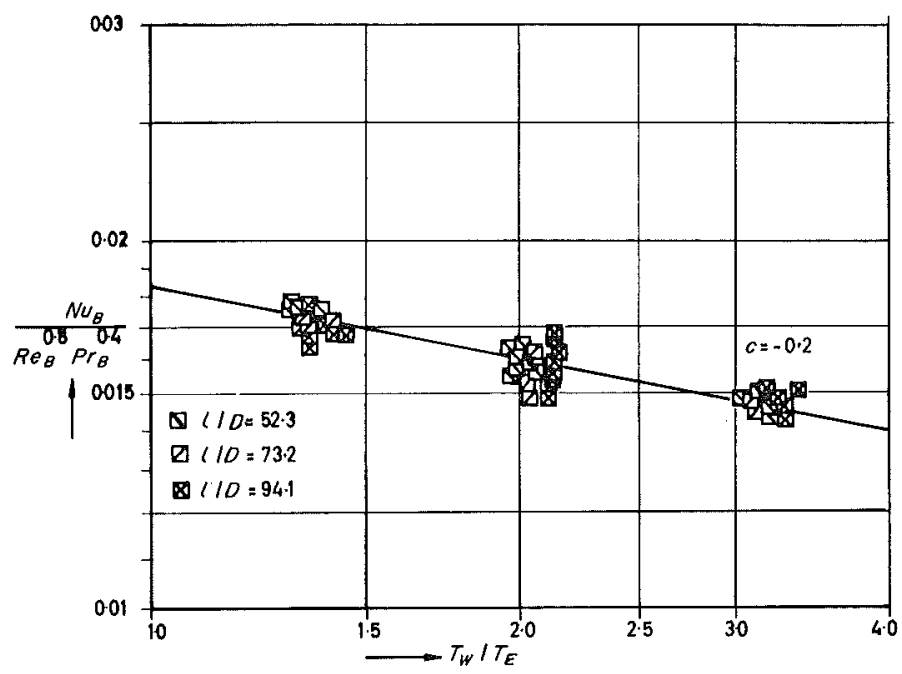

FIG. 13. Local heat transfer coefficients vs. $T_{W} / T_{E}, D_{2} / D_{1}=1 \cdot 38$.

closed geometry $T_{E}$ corresponds to $T_{\infty}$ for a free stream geometry, the assumption of $T_{W} / T_{E}$ as the characteristic temperature parameter implies that the thermal boundary layer in a duct develops, at least in the region nearest to the wall which is the most important for the heat-transfer coefficient, like that of a flat-plate. This assumption is perfectly reasonable because the thickness of the boundary laminar sublayer is always much smaller than the hydraulic radius of the duct. A more theoretical explanation, based on dimensional analysis is given in [22].

Figures 12 and 13 show the ratio $N u_{B}$ / $R e_{B}^{0.8} \mathrm{Pr}_{B}^{0.4}$ vs. $T_{W} / T_{E}$ for various $l / D$ 's and the two different values of $D_{2} / D_{1}$. The $l / D$ effect is practically eliminated for both test sections. The equations which correlate the points are the following:

$$
\begin{array}{r}
N u_{B}=0.0186 \operatorname{Re}_{B}^{0.8} \operatorname{Pr}_{B}^{0.4}\left(\frac{T_{W}}{T_{E}}\right)^{-0.2} \\
\text { for } \frac{D_{2}}{D_{1}}=1.99
\end{array}
$$

and

$$
\begin{aligned}
N u_{B}=0.0184 R e_{B}^{0.8} \operatorname{Pr}_{B}^{0.4}\left(\frac{T_{W}}{T_{E}}\right)^{-0.2} \\
\text { for } \frac{D_{2}}{D_{1}}=1.38
\end{aligned}
$$

Within the accuracy of the present experiment one can say that:

$\left(\frac{N u_{B}}{R e_{B}^{0 \cdot 8} \operatorname{Pr}_{B}^{0.4}}\right)_{T_{W} / T_{E}=1}=\left(\frac{N u_{B}}{R e_{B}^{0.8} P r_{B}^{0.4}}\right)_{T W / T_{B}=1}$

Therefore from equations (14)-(17) one has:

$N u_{B}=0.018\left(\frac{D_{2}}{D_{1}}\right)^{0.16 \xi} \operatorname{Re}_{B}^{0.8} \operatorname{Pr}_{B}^{0.4}\left(\frac{T_{W}}{T_{E}}\right)^{-0.2}$.

The exponent of the parameter $T_{W} / T_{E}$ found in the present experiment is rather close to the one found previously by the authors also for annuli $(-0 \cdot 18)[4]$, but smaller than the values found for a tube: -0.255 for a tube with long 
unbeated entrance length, and -0.304 for a tube with short entrance length $[2,3]$. This could possibly be due to the same uncertainties discussed above for the exponent $C$, or could be due to the different geometry (annulus, tube with long unheated entrance length, tube with short entrance length).

\section{SEPARATION OF THE INNER AND OUTER REGION OF THE ANNULI}

As one can see from equations (15) and (16), the heat transfer coefficients for the annuli investigated in the present experiment are about 20 per cent lower than those for the flow inside a circular tube, where the coefficient $A$ is generally taken as equal to 0.022 [1]. This had to be expected because, contrary to the latter, in an annulus, heat is transferred beyond the shear-stress-equal-zero line towards the outer region of the annulus. To compare our experiments with the data for a circular tube we devised a method to separate the outer from the inner region of the annulus. This method will be also useful to evaluate the experimental data with an annulus having an inner rough rod.

Originally it was assumed by Hall [23] that the separation line, i.e. the line for $\tau=0$, was coincident with the line of maximum velocity. Kjellström and Hedberg showed that these two lines were not coincident in turbulent regime and in presence of central rough rods [24], i.e. in presence of a strongly not-symmetrical velocity profile, possible also with smooth annuli with small $D_{1} / D_{2}$ ratios. This discrepancy has been investigated in more detail and confirmed by many experimental results in a recent paper of Maubach and Rehme [25].

We apply here a method suggested by $\mathrm{K}$. Maubach [26] which satisfies the experiments of Kjellström and Hedberg. This method was developed for isothermal conditions, and we extended it to the case of heat transfer to the fluid, with the assumption that the velocity profile, in terms of the law of the wall, is not affected by the temperature profile. This is legitimate within the conditions of the present experiment, as we have already discussed in section 3.1 (see also Figs. 2 and 3). Nikuradse found that the velocity profile in a smooth circular tube is given by [27]:

$$
u^{+}=2.5 \ln y^{+}+5.5 \text {. }
$$

Maubach assumes that this velocity profile is valid for the outer and inner regions of an annulus and that the line $\tau=0$ is given by the intersection of the two velocities profiles starting from the respective walls. Although mathematically at this intersection the velocity has a maximum, he shows that the agreement with the line $\tau=0$ experimentally determined by Kjellström and Hedberg is excellent. At the intersection one has:

$$
\begin{aligned}
& \frac{u_{\max }}{\sqrt{ }\left(\tau_{1} / \rho_{1}\right)}=2.5 \ln \left[\frac{r_{0}-r_{1}}{v_{1}} \sqrt{ }\left(\tau_{1} / \rho_{1}\right)\right]+5.5 \\
& \frac{u_{\max }}{\sqrt{ }\left(\tau_{2} / \rho_{2}\right)}=2.5 \ln \left[\frac{r_{2}-r_{0}}{v_{2}} \sqrt{ }\left(\tau_{2} / \rho_{2}\right)\right]+5.5
\end{aligned}
$$

Integrating equation (19) in the two regions one obtains the friction factors for the inner and outer regions of the annulus:

$$
\begin{aligned}
& \sqrt{\left(\frac{2}{f_{1}}\right)}=2.5 \ln \left[\frac{r_{0}-r_{1}}{v_{1}} \sqrt{\left.\left(\frac{\tau_{1}}{\rho_{1}}\right)\right]+5.5-G_{1}}\right. \\
& \sqrt{\left(\frac{2}{f_{2}}\right)}=2.5 \ln \left(\frac{r_{2}-r_{0}}{v_{2}} \sqrt{\left.\left(\frac{\tau_{2}}{\rho_{2}}\right)\right]+5.5-G_{2}}\right.
\end{aligned}
$$

where

$$
\begin{aligned}
G_{1} & =\frac{3 \cdot 75 K_{0}+1 \cdot 25 r_{0} / r_{1}}{1+r_{0} / r_{1}} \\
G_{2} & =\frac{3 \cdot 75 K_{0}+1 \cdot 25 r_{0} / r_{2}}{1+r_{0} / r_{2}}
\end{aligned}
$$

and $K_{0}=1.0576$ is an empirical factor which takes into account in the integration of the 
laminar sublayer near the surface. Taking the definitions:

$$
r_{1} / r_{2}=\alpha \quad r_{0} / r_{2}=\beta
$$

considering that

$$
\sqrt{ }(\tau / \rho)=\bar{u} \sqrt{ }\left(f_{B} / 2\right)
$$

that the pressure drops is the same for both regions:

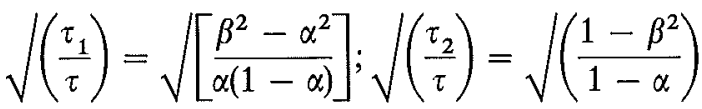

considering furthermore the definition of $R e_{B}$, from equations (20), (21) and (24)-(26) it follows: given by a "law of the wall" of the type:

$$
t^{+}=A_{s} \ln y^{+}+B_{s}
$$

For the inner region of the annulus, between $r=r_{1}$ and $r=r_{0}$, the integration of equation (28) gives:

$$
\begin{aligned}
q T_{1}=T_{W 1}- & \frac{q_{q 1}^{\prime}}{\rho_{1} c_{p 1} u^{*}}\left\{A_{s} \ln \frac{\left(r_{0}-r_{1}\right) u_{1}^{*}}{v_{1}}\right. \\
& \left.+B_{s 1}-A_{s} \frac{1 \cdot 5+0 \cdot 5 \beta / \alpha}{1+\beta / \alpha}\right\}
\end{aligned}
$$

where

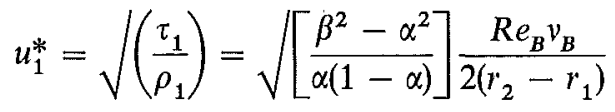

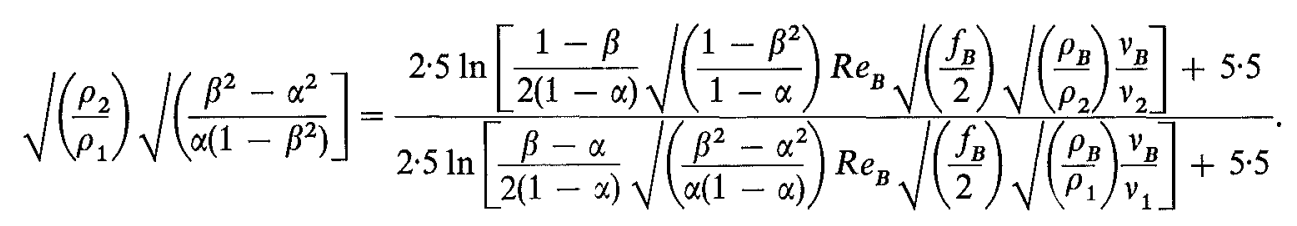

$R e_{B}$ and $f_{B}$ are measured in the experiment (see equation (3)), $\rho_{B}$ and $v_{B}$ are known because we measure gas pressure and temperature along the tube, $\alpha$ is measured accurately for each test section at the beginning of the test, $v_{1}, v_{2}, \rho_{1}$ and $\rho_{2}$ are known once the mean gas temperatures $T_{1}$ and $T_{2}$ in the two regions of the annulus are known, so that the only unknown $\beta$, which determines the separation line between the two regions, can be obtained by equation (27).

Determination of two mean gas temperatures $\mathrm{T}_{1}$ and $\mathrm{T}_{2}$

Our extension of the Maubach method consists in the derivation of equation (27) in which it is taken into account of the different physical properties of the two regions of the fluid. To do so, it is necessary to evaluate the mean gas temperatures $T_{1}$ and $T_{2}$ of the two regions. We assume with Gowen and Smith $[28,29]$ that the temperature profiles in the two regions are $\times \sqrt{\left(\frac{f_{B}}{2}\right)} \sqrt{ }\left(\frac{\rho_{B}}{\rho_{1}}\right)($ from equations (25) and (26)) and $q$ is a correction factor which will be determined by the heat balance, how explained below.

For the outer region of the annulus, between $r=r_{0}$ and $r=r_{2}$, the integration of equation (29) gives:

$$
\begin{aligned}
q T_{2} & =\frac{\delta^{2}-\beta^{2}}{1-\beta^{2}}\left\{T_{W 1}-\frac{q_{q 1}^{\prime}}{\rho_{1} c_{p 1} u_{1}^{*}}\right. \\
& \left.\times\left[B_{s 1}-A_{s}\left(\frac{1}{2}+\frac{\alpha}{\delta+\beta}\right)\right]\right\}+\frac{A_{s}}{\lambda-\beta^{2}} \\
& \times \frac{q_{g 1}^{\prime}}{\rho_{1} c_{p 1} u_{1}^{*}}\left[\left(\delta^{2}-\alpha^{2}\right) \ln \left(\frac{r_{m}-r_{1} u_{1}^{*}}{v_{1}}\right)\right. \\
& \left.-\left(\beta^{2}-\alpha^{2}\right) \ln \left(\frac{r_{0}-r_{1}}{v_{1}} u_{1}^{*}\right)\right]+\frac{1-\delta^{2}}{1-\beta^{2}} \\
& \times\left\{T_{W 2}-\frac{q_{g 2}^{\prime}}{\rho_{2} c_{p 2} u_{1}^{*}}\left[B_{s 2}-A_{s}\left(\frac{1}{2}+\frac{1}{1+\delta}\right)\right.\right.
\end{aligned}
$$




$$
\left.\left.+A_{s} \ln \left(\frac{r_{2}-r_{m}}{v_{2}} u_{2}^{*}\right)\right]\right\}
$$

where

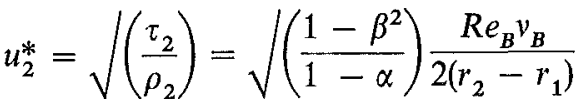

$$
\begin{aligned}
& \times \sqrt{\left(\frac{f_{B}}{2}\right)} /\left(\frac{\rho_{B}}{\rho_{2}}\right) .
\end{aligned}
$$

At the line of intersection between the two temperatures profiles for $r=r_{m},\left(r_{m} / r_{2}=\delta\right)$, the gas temperature has a minimum, and for continuity one has:

$$
\begin{aligned}
& T_{W 1}-\frac{q_{g 1}^{\prime}}{\rho_{1} c_{p 1} u_{1}^{*}}\left[A_{s} \ln \left(\frac{r_{m}-r_{1}}{v_{1}} u_{1}^{*}\right)+B_{s 1}\right] \\
& =T_{W 2}-\frac{q_{g 2}^{\prime}}{\rho_{2} c_{p 2} u_{2}^{*}}\left[A_{s} \ln \left(\frac{r_{2}-r_{m}}{v^{2}} u_{2}^{*}\right)+B_{s 2}\right] .
\end{aligned}
$$

that is:

$$
\begin{aligned}
& c_{p B}\left(T_{B n}-T_{B(n-1)}\right)=\frac{r_{0}^{2}-r_{1}^{2} \rho_{1} \vec{u}_{1}}{r_{2}^{2}-r_{1}^{2}} \frac{\rho_{B} u_{B}}{\times} c_{p 1}\left(T_{1 n}-T_{1(n-1)}\right) \\
& \quad+\frac{r_{2}^{2}-r_{0}^{2} \rho_{2} \bar{u}_{2}}{r_{2}^{2}-r_{1}^{2}} \frac{{ }_{2}{ }_{B} u_{B}}{\rho_{p 2}}\left(T_{2 n}-T_{2(n-1)}\right) .
\end{aligned}
$$

From equations (24)-(26) one obtains:

$$
\begin{aligned}
\frac{r_{0}^{2}-r_{1}^{2}}{r_{2}^{2}-r_{1}^{2}} \frac{\rho_{1} \bar{u}_{1}}{\rho_{B} u_{B}}= & \frac{\beta^{2}-\alpha^{2}}{1-\alpha^{2}} \sqrt{\left[\frac{\beta^{2}-\alpha^{2}}{\alpha(1-\alpha)}\right]} \\
& \times \sqrt{ }\left(f_{B} / f_{1}\right) \sqrt{ }\left(\rho_{1} / \rho_{B}\right)=C \\
\frac{r_{2}^{2}-r_{0}^{2}}{r_{2}^{2}-r_{1}^{2}} \frac{\bar{u}_{2}}{\rho_{B} u_{B}} & =\frac{1-\beta^{2}}{1-\alpha^{2}} \sqrt{\left[\frac{1-\beta^{2}}{1-\alpha}\right]} \\
& \times \sqrt{ }\left(f_{B} / f_{2}\right) \sqrt{ }\left(\rho_{2} / \rho_{B}\right)=D
\end{aligned}
$$

(31) and equation (35) can be written as:

$$
\frac{1}{q}=\frac{c_{p B}\left(T_{B n}-T_{B(n-1)}\right)+C_{c_{p 1}} T_{1(n-1)}+D c_{p 2} T_{2(n-1)}}{c_{p 1} q T_{2} C+c_{p 2} q T_{2} D} .
$$

Furthermore from equations (22), (23), (25) and (26) one obtains:

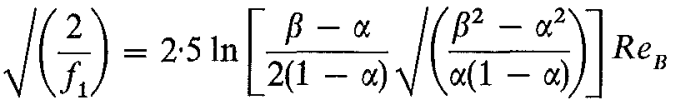

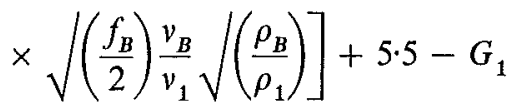

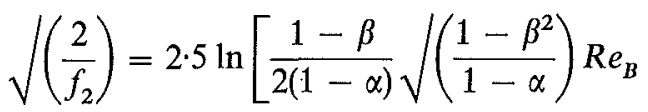

$$
\begin{aligned}
& \times \sqrt{\left(\frac{f_{B}}{2}\right) \frac{v_{B}}{v_{2}}} \sqrt{\left.\left(\frac{\rho_{B}}{\rho_{2}}\right)\right]+5 \cdot 5-G_{2} .}
\end{aligned}
$$

The heat balance is given by:

$$
\begin{aligned}
& \pi\left(r_{2}^{2}-r_{1}^{2}\right) \rho_{B} u_{B} c_{p B}\left(T_{B n}-T_{B(n-1)}\right) \\
& \quad=\pi\left(r_{0}^{2}-r_{1}^{2}\right) \rho_{1} \bar{u}_{1} c_{p 1}\left(T_{1 n}-T_{1(n-1)}\right) \\
& \quad+\pi\left(r_{2}^{2}-r_{0}^{2}\right) \rho_{2} \bar{u}_{2} c_{p 2}\left(T_{2 n}-T_{2(n-1)}\right)
\end{aligned}
$$

$\beta, \delta, T_{1}$ and $T_{2}$ are calculated by iteration. In the first iteration one assumes $T_{1}=T_{2}=T_{B} ; \beta$ is given by equation (27) and $\delta$ from equation (31). From equations (29) and (30) the products $q T_{1}$ and $q T_{2}$ are calculated. $C$ and $D$ are calculated with equations (36), (32) and (33), therefore it is possible to obtain, from equation (37) the value of $1 / q$. The calculation is repeated until two subsequent values of $q$ differ less than 1 per cent. The value of $A_{s}$ was assumed in the calculations to be constant and equal to $2 \cdot 2$ according to the measurements of Gowen and Smith [28], while the value of $B_{s}$ was assumed to be dependent upon the ratio $T_{W} / T_{B}$; indeed, while $A_{s}$ characterizes the temperature distribution in the fluid at a distance from the wall, $B_{s}$ is the most important term near the wall, where, in presence of a large temperature difference between wall and fluid, most of this difference is concentrated. It is logical therefore to assume 


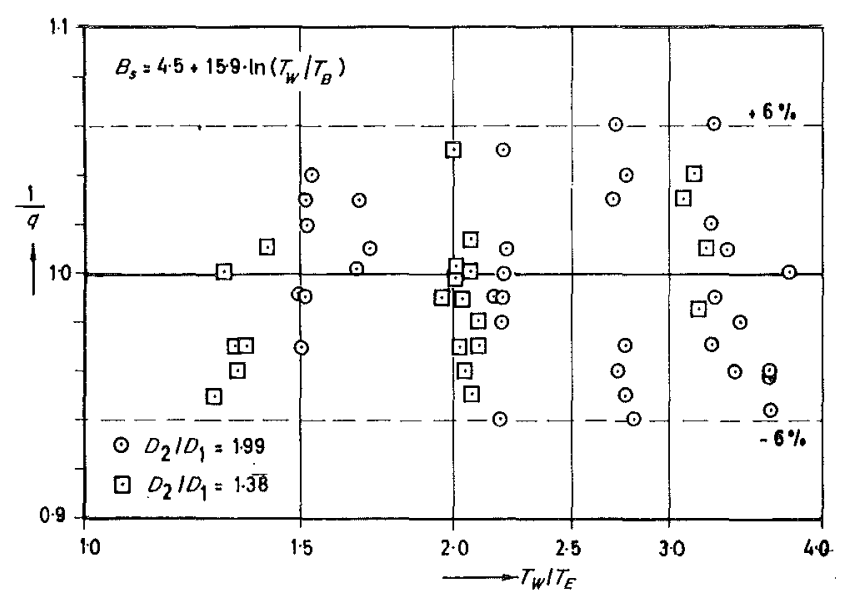

FIG. $14.1 / q$ for $B_{s}=4 \cdot 5+15.9 \ln \left(T_{W} / T_{B}\right)$.

that the effect of the variation of the fluid properties on the temperature distribution is concentrated on $B_{s}$, in the same way as, for instance, the sand roughness on the wall effects only the constant part and not the coefficient of $\ln y^{+}$in equation (19) [30]. The relation between $B_{s}$ and $T_{W} / T_{B}$ is of course not known. We tried therefore various correlations until the corresponding obtained values of $q$ were as near as possible to the value 1 for all the experimental points and no systematic deviation of $q$ from 1 could be observed. In other words we tried to determine the relation between $B_{s}$ and $T_{W} / T_{B}$ indirectly from our measurements of wall temperatures, heat fluxes and from the heat balance. Figure 14 gives the values of $1 / q$ for the chosen correlation of $B_{s}$ :

$$
B_{s}=4 \cdot 5+15 \cdot 9 \ln \left(T_{W} / T_{B}\right)
$$

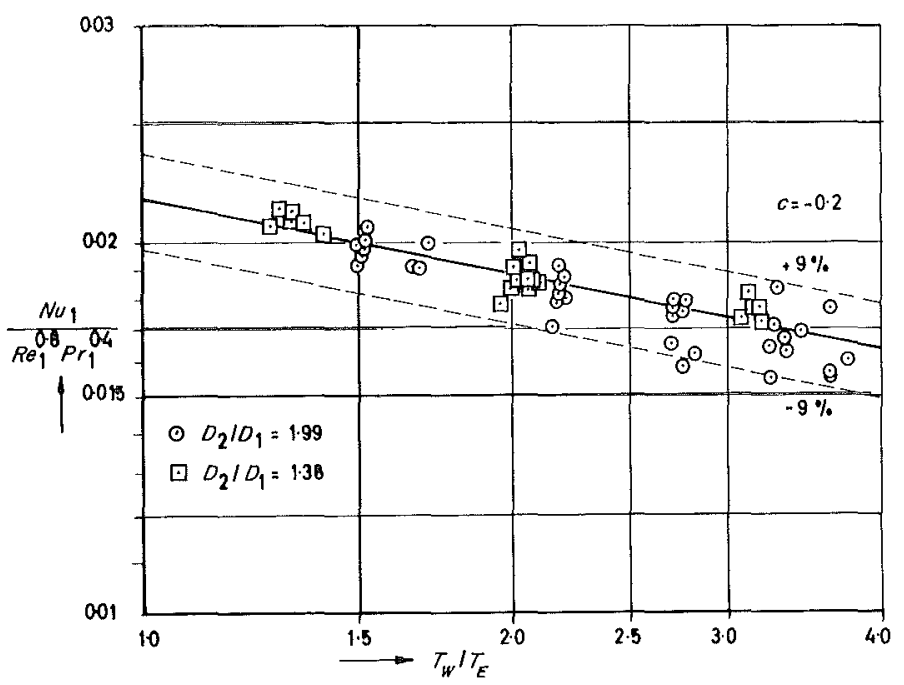

Fig. 15. Average heat transfer coefficients for the inner region of the annulus vs. $T_{W} / T_{E}$. 


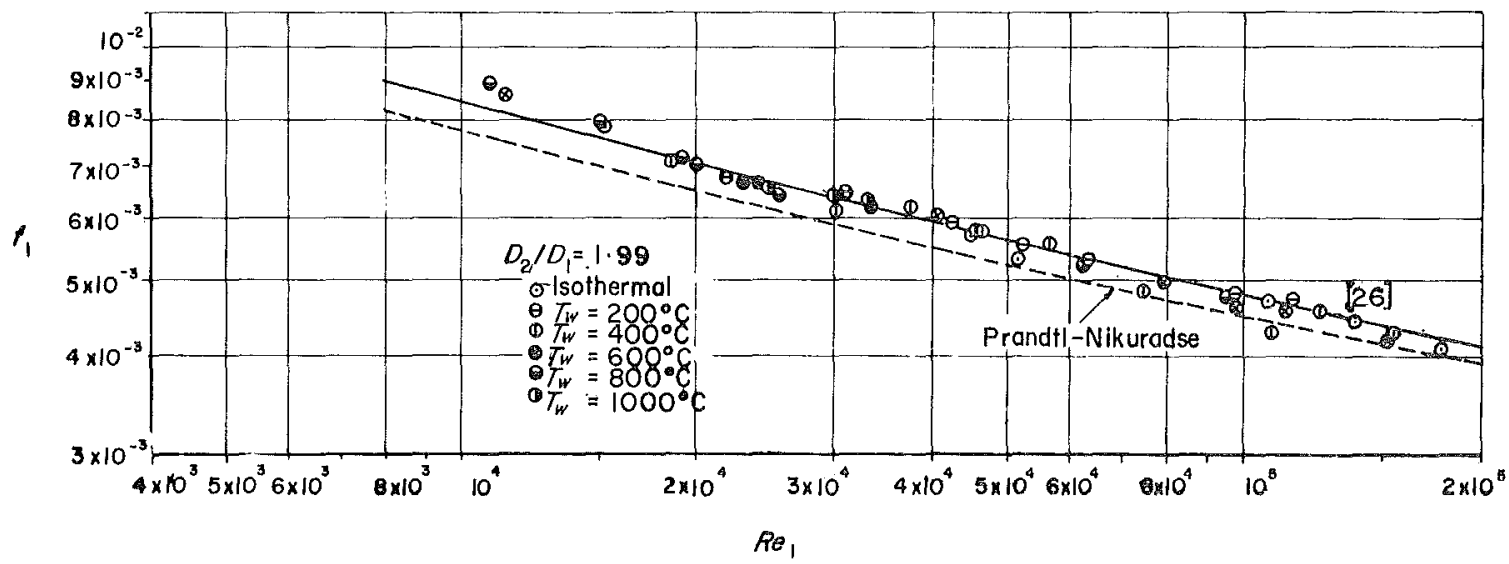

FIG. 16. Average friction coefficients for the inner region of the annulus, $D_{2} / D_{1}=1.99$.

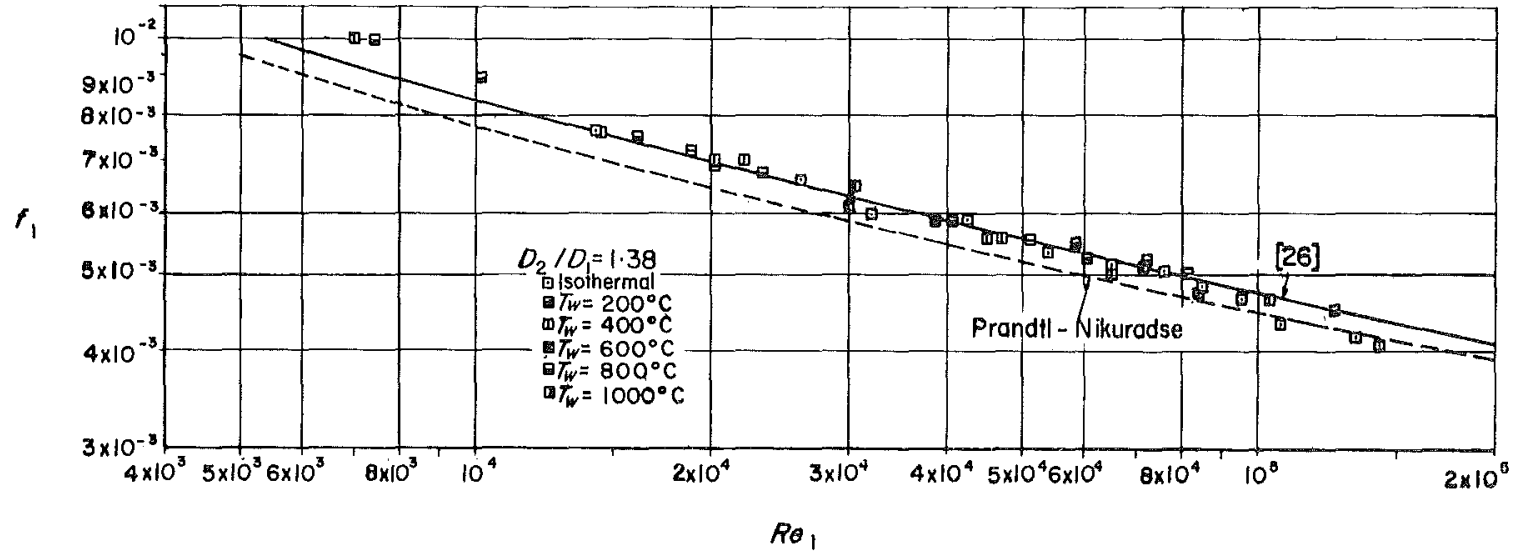

FIG. 17. Average friction coefficients for the inner region of the annulus, $D_{2} / D_{1}=1 \cdot 38$.

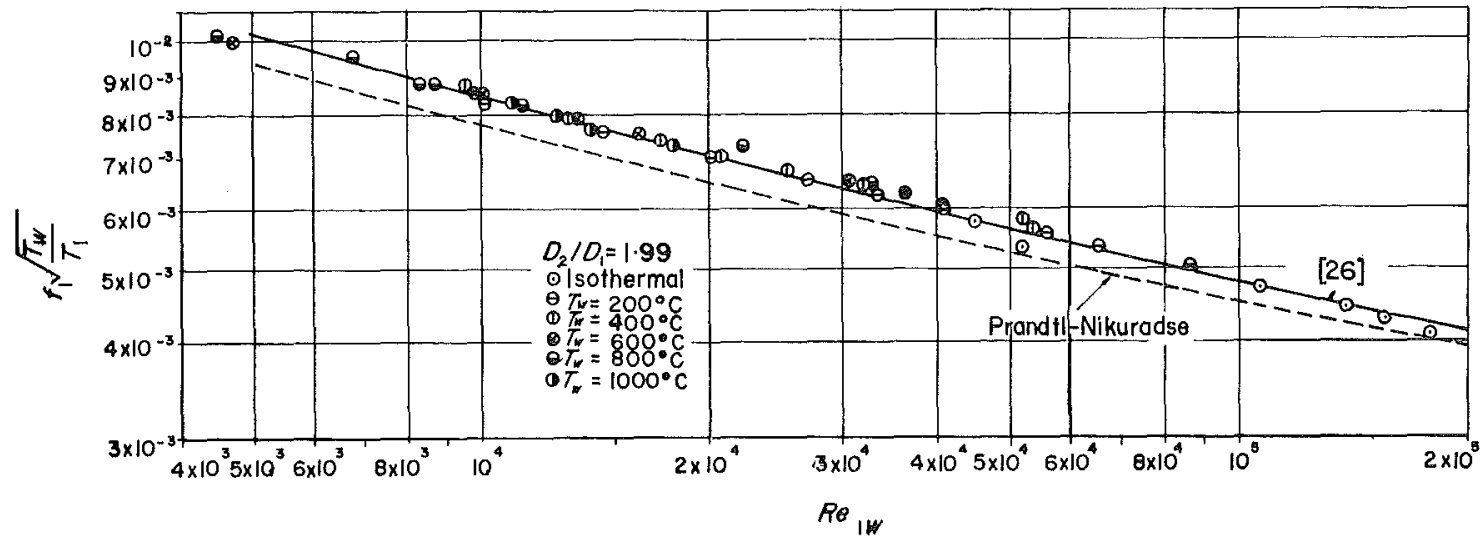

FIG. 18. Average friction coefficients for the inner region of the annulus, Taylor correlation, $D_{2} / D_{1}=1.99$. 


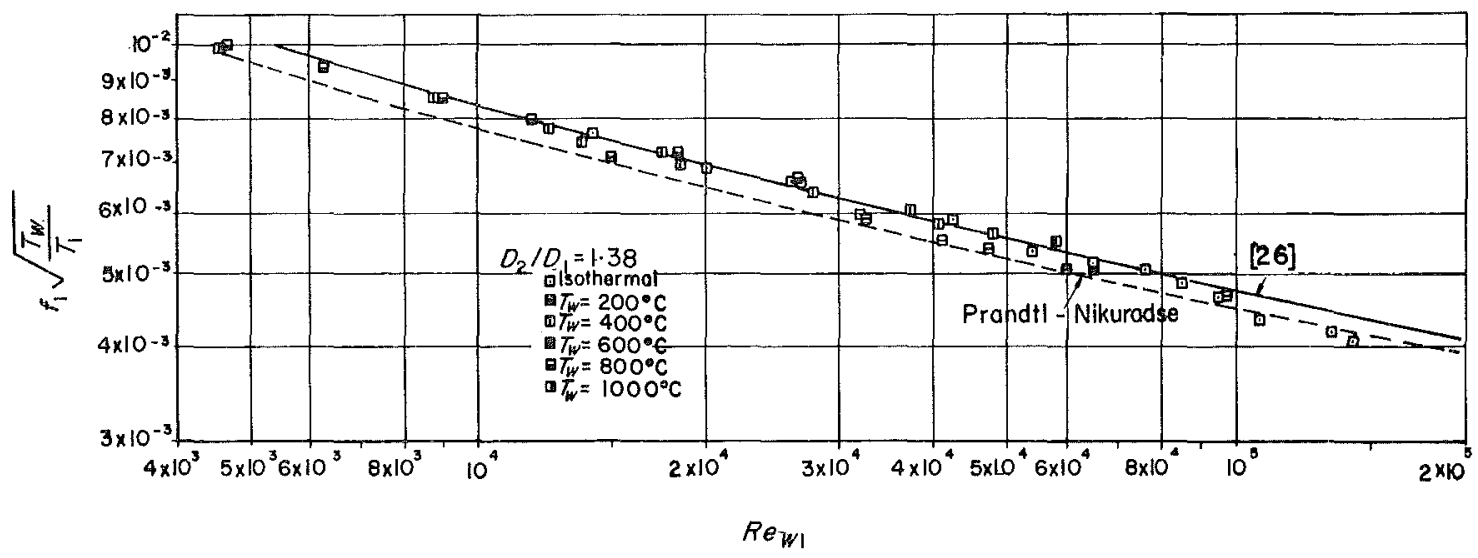

FIG. 19. Average friction coefficients for the inner region of the annulus, Taylor correlation, $D_{2} / D_{1}=1 \cdot 38$.

Once $T_{1}$ is known, $f_{1}$ is obtained from equation (32) and

$$
\begin{array}{r}
R e_{1}=R e_{B} \frac{\beta^{2}-\alpha^{2}}{\alpha(1-\alpha)} /\left[\frac{\beta^{2}-\alpha^{2}}{\alpha(1-\alpha)}\right] \\
\times \sqrt{\left(\frac{f_{B}}{f_{1}}\right) \sqrt{ }\left(\frac{\rho_{B}}{\rho_{1}}\right) \frac{v_{B}}{v_{1}}} \\
N u_{1}=\frac{q_{g 1}^{\prime}}{\left(T_{W 1}-T_{1}\right) k_{1}} \frac{\beta^{2}-\alpha^{2}}{\alpha} 2 r_{2} .
\end{array}
$$

Figure 15 shows the ratio $N u_{1} /\left(\operatorname{Re}_{1}^{0.8} \operatorname{Pr}_{1}^{0.4}\right)$ vs. $T_{W} / T_{E^{*}}$ Unlike in Figs. 12 and 13, here the values are averages, because the determination of $N u_{1}$ and $R e_{1}$ depend on the friction factor $f_{1}$ and, as we have explained in section 3.1 , the average values of the friction factors are less affected by measurement errors than the local values.

For both test sections the points can be correlated by:

$$
N u_{1}=0.0217 \operatorname{Re}_{1}^{0.8} \operatorname{Pr}_{1}^{0.4}\left(\frac{T_{W}}{T_{E}}\right)^{-0.2}
$$

which is in close agreement with the correlation recommended in [1] for flow in circular tubes.

Figures 16 and 17 show values of $f_{1}$ vs. $R e_{1}$ for the two test sections.

In [26] a friction correlation in isothermal conditions $(f=f(\operatorname{Re}, \alpha))$ for the whole of the annulus as well as for the inner and outer regions of the annulus was obtained from equations (22), (23) and the continuity condition. Figures 16 and 17 show an excellent agreement of this correlation with our experimental points for Reynolds numbers greater than 15000 . In Fig. 1 it is shown that the agreement of the correlation of [26] for the whole annulus with our experimental points is better than the PrandtlNikuradse law for circular tubes.

Figures 18 and 19 show $f_{1} \sqrt{ }\left(T_{W 1} / T_{1}\right)$ vs. $R e_{W 1}$, whereby in this case the values of $f_{1}$ and $R e_{W 1}$ have been obtained using $\rho_{x}, \rho_{1 x^{\prime}}, \rho_{2 x}$, $v_{W 1}, v_{W 1}, v_{W 2}$ in place of $\rho_{B}, \rho_{1}, \rho_{2}, v_{B}, v_{1}, v_{2}$, respectively in equations (27)-(37). The difference from Figs. 16 and 17 is here more marked than for the friction factors for the whole annulus (Figs. 3 and 4), due to the fact that the new values of $\rho$ and $\nu$ produce slightly different values of $\beta$ (position of the separation line between the two region of the annulus). The agreement with the correlations of [26] is excellent even for Reynolds numbers smaller than 15000, suggesting that the definition of the friction velocity given by equation (11) is applicable in presence of large temperature differences not only to tubes, as the experiments of Taylor show, but to annuli as well. 


\section{CONCLUSIONS}

Local heat transfer and averaged friction coefficients were measured for subsonic turbulent flow of air through two smooth annuli, with diameter ratios equal to 1.99 and 1.38 , respectively, having the inner tube heated up to temperatures of $1000^{\circ} \mathrm{C}$. The main experimental results can summarized as follows:

1. The local heat-transfer coefficients are correlated by:

$$
N u_{B}=0.018\left(\frac{D_{2}}{D_{1}}\right)^{0.16} \operatorname{Re}_{B}^{0.8} \operatorname{Pr}_{B}^{0.4}\left(\frac{T_{W}}{T_{E}}\right)^{-0.2}
$$

which gives the Petukhov and Roizen correlation [13] for low temperature differences

$$
\left(T_{W} / T_{E} \rightarrow 1\right)
$$

2. The average heat-transfer coefficients for the inner region of the annulus are correlated by:

$$
N u_{B}=0.0217 \operatorname{Re}_{B}^{0.8} \operatorname{Pr}_{B}^{0.4}\left(\frac{T_{W}}{T_{E}}\right)^{-0.2}
$$

in excellent agreement with data for circular tubes (Dalle Donne-Bowditch correlation [1]).

3. The friction coefficients, both for the whole annulus and the inner region of it, are in excellent agreement with the correlations of Maubach [26] obtained by integration of the universal velocity profile of Nikuradse, provided that density of the fluid is evaluated at the temperature $T_{x}=\sqrt{ }\left(T_{W} . T_{B}\right)$ and the kinematic viscosity at the temperature $T_{W}$, as suggested by the experiments of Taylor for circular tubes [6].

\section{ACKNOWLEDGEMENTS}

The authors wish to thank Mr. D. Artz and Mr. F. Merschroth for their help in the construction of the rig, in performing the experiments, the numerical calculations and the graphs.

\section{REFERENCES}

1. M. Dalle Donne and F. H. Bowditch, Experimental local heat transfer and friction coefficients for subsonic laminar, transitional and turbulent flow of air or helium in a tube at high temperatures, Dragon Project Report 184, April 1963

2. M. Dalle Donne and F. H. Bowditch, Local heat transfer and average friction coefficients for subsonic laminar, transitional and turbulent flow of air in a tube at high temperature, Dragon Project Report 88, March 1962, and Nucl. Engng 19638 (80), 20-29 (1963).

3. M. Dalle Donne, High temperature gas heat transfer in tubes, Trans. ANS 2 (2), 506 (1964).

4. M. Dalle Donne and E. Meerwald, Experimental local heat transfer and average friction coefficients in an annulus at high temperatures, Int. J. Heat Mass Transfer 9, 1361-1373 (1966).

5. H. Schlichting, Boundary Layer Theory, Ch. XX. McGraw-Hill, New York (1954).

6. M. F. TAYLOR, A method of correlating local and average friction coefficients for both laminar and turbulent flow of gases through a smooth tube with surface to fluid bulk temperature ratios from 0.35 to 7.35, Int. J. Heat Mass Transfer 10, 1123-1128 (1967).

7. V. L. LeL'CHUCK and B. V. DyAdYaKin, Heat transfer from a wall to a turbulent current of air within a tube and the hydraulic resistance at high temperature differentials, Problems of Heat Transfer, AEC-tr-4511 (1962).

8. V. L. LeL'CHUCK and G. I. ElFimov, Investigation data of local heat transfer from tube wall heated up to $1000^{\circ} \mathrm{C}$ to gases with different atomicity at turbulent flow, Teplo i Massoperenos 1, 465-474. Energija, Moskva (1968).

9. V. L. Lel'chuck, K. F. Shuiskaya and A. G. SoRokin, Turbulent heat transfer of argon flowing in pipes under wall-temperature up to $3000^{\circ} \mathrm{K}$, Fourth International Heat Transfer Conf., Vol. II FC4.2, Paris (1970).

10. M. F. TAYLOR, Experimental local heat-transfer data for precooled hydrogen and helium at surface temperatures up to $53000^{\circ} \mathrm{R}$, NASA TN D-2595 (1965).

11. A. C. RAPIER, Forced convection heat transfer in passages with varying roughness and heat flux around the perimeter, TRG Report 519 (1963).

12. P. I. PuChOV and O. S. Vinogradov, Heat transfer and hydraulic resistance in annular channels with smooth and rough heat transfer surfaces, Heat and Mass Transfer, Vol. I. Nauka i Tekhnika, Minsk (1965).

13. B. S. Petukhov and L. I. Roizen, Heat exchange and friction resistance in pipes and channels of various geometrical shapes, Heat and Mass Transfer, Vol. I. Nauka i Tekhnika, Minsk (1965).

14. H. BARTHELS, Darstellung des Wärmeübergangs in konzentrischen Ringspalten unter Benutzung der Analogie zwischen Impuls- und Wärmeaustausch, Jül-506RB (1967).

15. N. W. Wilson and S. O. Medwell, An analysis of heat transfer for fully developed turbulent flow in concentric annuli, J. Heat Transfer 90C, 43-50 (1968).

16. W. M. KAYS and E. Y. LeUNG, Heat transfer in annular passages. Hydrodynamically developed turbulent flow with arbitrary prescribed heat flux, Int. J. Heat Mass Transfer 6, 548 (1963).

17. N. I. BuleEv, V. A. Molosova and L. D. Yel'Tsova, Wärmeübergang in turbulenten Strömungen in Ringspalten und flachen Spalten, Zhidkie Metally, Sbermik statey. Atomizdat, Moskau (1967).

18. N. I. Buleev, V. A. Molosova and L. D. El'tsova, 
Turbulent flows of a liquid in annular and plane channels, translated from Teplofiz. Vysok. Temp. (High Temperature) 5 (4), 630-639 (1967).

19. R. G. Deissler and M. F. TAYLOR, Analysis of fully developed turbulent heat transfer and flow in an annulus with various excentricities, NACA-TN-3451 (1955).

20. B. N. Furber, W. J. Green and W. R. Vivian, Heat transfer in the entrance region of an annulus, Heat Transfer 1970, Vol. II, FC 3.3 (1970).

21. M. Dalle Donne and E. Meerwald, Heat transfer from surfaces roughened by thread-type ribs at high temperatures, Proc. 1970 Heat Transfer and Fluid Mechanics Institute. Stanford Univ. Press, Stanford, Calif. (1970).

22. M. Dalle Donne, Authors' replies, Proc., Conf. High Pressure Gas as a Heat Transfer Medium, Inst. Mech. Engrs, Vol. 181, Part 3I, 261-262 (1967).

23. W. B. HALl, Heat transfer in channels having rough and smooth surfaces, J. Mech. Engng Sci. 4 (3), (1962).

24. B. KJELlström and S. HedBerg, On shear stress distribution for flow in smooth or partially rough annuli, paper presented at the E.A.E.S. Heat Transfer Symposium on Superheated Steam or Gas, Bern, Switzerland (Sept. 1966).
25. K. MAUBach and K. ReHme, Negative eddy diffusivities for asymmetric turbulent velocity profiles, Int. J. Heat Mass Transfer 15, 425 (1972).

26. K. MAUBACH, Reibungsgesetze turbulenter Strömungen in geschlossenen glatten und rauhen Kanälen von beliebigem Querschnitt, Externer Bericht INR-4/69-22, Kernforschungszentrum Karlsruhe, West Germany (March 1969); see also, Reibungsgesetze turbulenter Strömungen, Chemie-Ing. Technik 15, 995-1004 (1970).

27. J. NikURADSE, Gesetzmässigkeiten der turbulenten Strömung in glatten Rohren, VDI-Forsch. 356 (1932).

28. R. A. Gowen and J. W. SMITH, The effect of the Prandtl number on the temperature profiles for heat transfer in turbulent pipe flow, Chem. Engng Sci. 22, 1701-1711 (1967).

29. R. A. Gowen and J. W. SMrth, Turbulent heat transfer from smooth and rough surfaces, Int. J. Heat Mass Transfer 11, 1657-1673 (1968).

30. J. NikuRADSE, Strömungsgesetze in rauhen Rohren, VDI-Forsch. 361 (1933).

31. N. Sheriff and P. Gumley, Heat transfer and friction properties of surfaces with discrete roughness, Int. J. Heat Mass Transfer 9, 1297 (1966).

\section{COEFFICIENT DE TRANSFERT DE CHALEUR ET DE FROTTEMENT POUR L'ÉCOULEMENT TURBULENT D'ATR DANS LES CANAUX ANNULAIRES LIS $\AA$ HAUTES TEMPÉRATURES}

Résumé-On a mésure les coefficients du transfert local de chaleur et les coefficients moyens de frottement pour un courant turbulent subsonique d'air passant par deux espaces annulaires lisses aux rapports diamétriques de 1.99 respectivement de 1.38. La tube intérieure a été chauffée jusqu'à des températures de $1000^{\circ} \mathrm{C}$. Les principaux résultats expérimentaux obtanus se résument comme suit:

1. Il existe une corrélation entre les coefficients de transfert de chaleur par

$$
N u_{B}=0.018\left(\frac{D_{2}}{D_{1}}\right)^{0.16} \operatorname{Re}_{B}^{0.8} \operatorname{Pr}_{B}^{0.4}\left(\frac{T_{W}}{T_{E}}\right)^{-0.2}
$$

ce qui donne la corrélation de Petukhov et de Roizen [13] pour les petites différences de température $\left(T_{W} / T_{E} \rightarrow 1\right)$.

2. Une corrélation existe entre les coefficients moyens de transfert de chaleur pour la région intérieure de l'espace annulaire par

$$
N u_{B}=0.0217 \operatorname{Re}_{B}^{0.8} \operatorname{Pr}_{B}^{0.4}\left(\frac{T_{W}}{T_{E}}\right)^{-0.2}
$$

ce qui fournit un accord excellent avec les données valables pour les tubes circulaires (corrélation de Dalle Donne et de Bowditch [1]).

3. Les coefficients de frottement pour l'ensemble de l'espace annulaire ainsi que pour sa région intérieure sont en tres bon accord avec les corrélations de Maubach [26] obtenues en intégrant le profil universel de vitesse de Nikuradse sous condition que la densité du fluide soit déterminée à la température $T_{x}=$ $\sqrt{ }\left(T_{W}: T_{B}\right)$ et la viscosité cinématique à la température $T_{W}$ ce que suggèrent les expériences de Taylor sur des tubes circulaires [6]. 


\section{WÄRMEÜBERGANG UND REIBUNGSKOEFFICIZIENTEN FÜR TURBULENTE LUF'TSTRÖMUNG IN GLATTEN RINGRÄUMEN BEI HOHEN TEMPERATUREN}

Zusammenfassung Gemessen wurden die lokalen Wärmeübergangs- und mittleren Reibungskoeffizienten einer turbulenten Unterschall-Luftströmung durch zwei glatte Ringräume mit einem Durchmesserverhältnis von 1.99 bzw. 1.38. Das innere Rohr wurde auf Temperaturen bis $1000^{\circ} \mathrm{C}$ erhitzt. Die wichtigsten Versuchsergebnisse können wie folgt zusammengefasst werden:

1. Zwischen den lokalen Wärmeübergangskoeffizienten gilt die Beziehung

$$
N u_{B}=0.018\left(\frac{D_{2}}{D_{1}}\right)^{0.16} \operatorname{Re}_{B}^{0.8} \operatorname{Pr}_{B}^{0.4}\left(\frac{T_{W}}{T_{E}}\right)^{-0.2}
$$

was für kleine Temperaturdifferenzen $\left(T_{W} / T_{E} \rightarrow 1\right)$ die Korrelation von Petukhov und Roizen [13] ergibt. 2. Zwischen den mittleren Wärmeübergangskoeffizienten für den inneren Bereich des Ringraums gilt die Beziehung

$$
N u_{B}=0.0217 \operatorname{Re}_{B}^{0.8} \operatorname{Pr}_{B}^{0.4}\left(\frac{T_{W}}{T_{E}}\right)^{-0.2}
$$

und hier ergibt sich eine ausgezeichnete Ubereinstimmung mit den für kreisförmige Rohre gewonnenen Werten (Korrelation von Dalle Donne und Bowdicht [1]).

3. Die Reigunbskoeffizienten für den Gesamtringraum und für seinen inneren Bereich stimmen ausgezeichnet mit den Korrelationen von Maubach [26] überein, die man durch Integration des universellen Geschwindigkeitsprofils von Nikuradse erhält, wenn die Flüssigkeitsdichte bei Temperatur $T_{x}=\sqrt{ }\left(T_{W} . T_{n}\right)$ und die Bewegungszähigkeit bei Temperatur $T_{W}$ bestimmt werden, was aus den von Taylor mit kreisförnigen Rohren durchgeführten Experimenten hervorgeht [6].

КОӘФФИЦЕНТЫ ТЕПЛООБМЕНА И ТРЕНИЯ ПРИ ТУРБУЛЕНТНОМ ТЕЧЕНИИ ВОЗДУХА В КОЛЬЦЕВЫХ КАНАЛАХ С ГЛАДКИМИ СТЕНКАМИ ПРИ БОЛЬШИХ ЗНАЧЕНИЯХ ТЕМПЕРАТУРЫ

Аннотациц-Местные коәффиициенты теплоотдачи и средние гоәффпциенты трения измерены для дозвукового турбулентного потока воздуха через два плавных кольца; отношение диаметров равно 1,99 и 1,38 соответственно; внутренняя труба была разогрета до температур $1000^{\circ} \mathrm{C}$. Главные әкспериментальные результаты можно обобщать следующим образом :

1. Местные коәффициенты теплоотдачи коррелированы следующим соотношением :

$$
N u_{B}=0,018\left(\frac{D_{2}}{D_{1}}\right)^{0,16} \operatorname{Re}_{B}^{0,8} \operatorname{Pr}_{B} 0,4\left(\frac{T_{W}}{T_{E}}\right)^{-0,2}
$$

что дает корреляцию Петухова и Ройзена [13] для низкой равности температур $\left(T_{W} / T_{E} \rightarrow 1\right)$

2. Средние коәффициенты теплоотдачи для внутренней части кольца коррелированы следующим соотношением :

$$
N u_{B}=0,0217 \operatorname{Re}_{B} 0,8 \operatorname{Pr}_{B} 0,4\left(\frac{T_{W}}{T_{E}}\right)^{-0,2}
$$

что находится в весьма хорошем согласпи с данными для круглых труб (корреляция Даллэ Доннэ - Баудича [1]).

3. Коэффициенты трения, как для целого кольца, так и для его внутренней части, очень удовлетворитөльно совпадают с корреляциями Маубаха [26], полученными интегрированием универсального профиля скоростей Никурадзе, при условии, что плотность жидкости оценивается при температуре $T_{x}=\sqrt{ } T_{W} . T_{B}$ и кинематическая вязкость при температуре $T_{W}$, как әто следует из проведенных Тейлором опытов для круглых труб [6]. 
